OPEN ACCESS

Edited by: Stephan Vagner, Institut Curie, France

Reviewed by: Natalia Sanchez De Groot, Universitat Autònoma de Barcelona

Spain

Rachid Mazroui

Laval University, Canada

*Correspondence:

Tracy Nissan

t.nissan@sussex.ac.uk

Specialty section:

This article was submitted to

Protein and RNA Networks,

a section of the journal

Frontiers in Molecular Biosciences

Received: 30 December 2020

Accepted: 01 March 2021

Published: 29 April 2021

Citation:

Tweedie A and Nissan T (2021)

Hiding in Plain Sight: Formation

and Function of Stress Granules

During Microbial Infection

of Mammalian Cells.

Front. Mol. Biosci. 8:647884.

doi: 10.3389/fmolb.2021.647884

\section{Hiding in Plain Sight: Formation and Function of Stress Granules During Microbial Infection of Mammalian Cells}

\author{
Alistair Tweedie ${ }^{1}$ and Tracy Nissan ${ }^{1,2 *}$ \\ 1 Department of Biochemistry and Biomedicine, School of Life Sciences, University of Sussex, Brighton, United Kingdom, \\ ${ }^{2}$ Department of Molecular Biosciences, The Wenner-Gren Institute, Stockholm University, Stockholm, Sweden
}

Stress granule (SG) formation is a host cell response to stress-induced translational repression. SGs assemble with RNA-binding proteins and translationally silent mRNA. SGs have been demonstrated to be both inhibitory to viruses, as well as being subverted for viral roles. In contrast, the function of SGs during non-viral microbial infections remains largely unexplored. A handful of microbial infections have been shown to result in host SG assembly. Nevertheless, a large body of evidence suggests SG formation in hosts is a widespread response to microbial infection. Diverse stresses caused by microbes and their products can activate the integrated stress response in order to inhibit translation initiation through phosphorylation of the eukaryotic translation initiation factor $2 \alpha$ (elF2 $\alpha$ ). This translational response in other contexts results in SG assembly, suggesting that SG assembly can be a general phenomenon during microbial infection. This review explores evidence for host SG formation in response to bacterial, fungal, and protozoan infection and potential functions of SGs in the host and for adaptations of the pathogen.

\footnotetext{
Keywords: stress granules (SG), elF2 alpha, integrated stress response (ISR), unfolded protein response (UPR), PKR, PERK, GCN2, HRI
}

\section{INTRODUCTION}

Stress granules (SGs) are cytoplasmic structures that accumulate as foci in response to multiple cellular stresses. SGs generally assemble in response to these stresses through stress-induced inhibition of translation initiation. In mammals, this is commonly accomplished by activation of kinases that phosphorylate eukaryotic translation initiation factor $2 \alpha$ (eIF2 $\alpha$ ). This results in stalled $48 \mathrm{~S}$ translation initiation complexes on mRNAs and a reduction in translating ribosomes due to further elongation without initiation. These mRNAs, cleared of ribosomes, bind to RNA binding proteins, which facilitate the process of SG assembly. Over time, assembled SGs can gain altered properties as well as recruit many additional mRNAs and proteins.

Central to the assembly of SGs, are the RNA binding proteins TIA1, TIAR, and G3BP1, which oligomerize on non-translating mRNA present in the granules. These, and other proteins, have multiple low-affinity interactions with both RNA and proteins, of which G3BP1 appears to be the central essential factor (Guillén-Boixet et al., 2020; Sanders et al., 2020; Yang et al., 2020; 
Hofmann et al., 2021). The proteins involved often contain intrinsically disordered regions and/or low complexity prion-like repeat sequences. These weak dynamic interactions act together to undergo the process of liquid-liquid phase separation (LLPS). This process concentrates proteins and RNA within the SGs to create a distinct fluid environment.

In infection biology, viruses were found to assemble SGs in response to viral infections soon after the discovery of SGs. Sensors for cellular stresses, such as the presence of endoplasmic reticulum (ER) stress, dsRNA, or amino acid starvation activate eIF2 $\alpha$ kinases. Viruses were recognized early as potential activators as they often contain dsRNA or cause ER stress, commonly from viral protein production (Anderson and Kedersha, 2002).

Translation inhibition that results in SG assembly is an important response of the cell to restrict viral protein production and replication. A clue to the importance of SGs is the multiple ways in which viruses affect them (White and Lloyd, 2012). Manipulation of SGs by viruses can include eIF2 $\alpha$-independent SG assembly, inhibition of SG assembly (either by other stresses or by viruses), or even subversion of SG proteins for new functions and novel non-SG-like aggregates, which are used for viral purposes, including viral replication.

More recent evidence suggests that SGs function in innate immunity in combatting viruses, independently of the role of translation inhibition (Lloyd, 2012; Onomoto et al., 2014; McCormick and Khaperskyy, 2017; Eiermann et al., 2020). These functions are primarily linked to sequestration of proteins and RNA within SGs, including translation initiation factors, RNA binding proteins involved in viral replication and signaling molecules. Beyond affecting translation, the sequestration inhibits viral replication and cellular apoptosis. Further evidence of the importance of SGs in combatting viral infections is that many viruses show increased viral production without SGs. Conversely, in other cases in which SG assembly cannot be subverted by viruses, there is a reduction in viral infection due to SGs.

In contrast to the well-studied effects of viruses on SGs, the role of bacterial, fungal, and protozoan infection in mammalian cells has remained largely unexplored. We argue in this review that there exists substantial experimental evidence that microbial infection is likely to result in host SG assembly. In addition, existing evidence suggests that specific microbial mechanisms to prevent or subvert SG assembly or proteins can exist, which are likely to be important for infection.

\section{MODULATION OF STRESS GRANULES IN HOST CELLS AS A RESPONSE TO MICROBIAL INFECTION}

Signaling upstream of SG assembly in host cells can be activated by non-viral microbial infection. This has been studied in a number of microorganisms. In contrast, the resulting effect on SGs remains largely unexamined (Table 1). Essentially, the presence or effect of microbial infection on host cell SG formation has only been examined in a handful of organisms. These include the Gram-negative Salmonella and Shigella bacteria, the Grampositive bacteria Listeria, and the protozoan parasite Plasmodium.

The first microbes demonstrated to cause host SG formation were the bacteria Salmonella typhimurium and Shigella flexneri (Tattoli et al., 2012; Vonaesch et al., 2016; Abdel-Nour et al., 2019). These were identified with SG marker proteins including TIA1 and another SG component, the translation initiation factor eIF3b.

Salmonella infection resulted in a transient induction of $\mathrm{TIA}^{+}{ }^{+}$SGs at 1-2 $\mathrm{h}$ post infection (hpi) (Tattoli et al., 2012). A later study quantitated the percentage of Salmonella-infected MEF cells containing SGs, finding it to be relatively low (AbdelNour et al., 2019). The percentage of SGs increased over time from $2 \%$ at $30 \mathrm{~min}$ to $5 \%$ at $5 \mathrm{hpi}$. The SGs were phosphorylated eIF $2 \alpha$ (P-eIF2 $\alpha$ ) dependent, as they were not observed in the non-phosphorylatable eIF2 $\alpha$ mutant (S51A) knock-in.

Shigella infection presents an interesting case of host SG modulation. Shigella-infected cells exhibited a more robust host SG response beginning with $5 \%$ of the cells exhibiting TIA $1^{+}$ SGs at $30 \mathrm{~min}$, increasing to $30 \% \mathrm{SGs}$ at $5 \mathrm{hpi}$, which were dependent on P-eIF2 $\alpha$ for assembly. A similar result was reported by another group using HeLa cells (Vonaesch et al., 2016). In this study, around $5 \%$ of the cells had eIF3b ${ }^{+}$SGs, while noninvasive Shigella lacking the virulence plasmid did not exhibit any SG formation. However, Shigella infection was associated with a reduction in drug-induced SGs, dependent on the presence of the virulence plasmid. This was further examined by pre-infection and subsequent exposure to the drugs for $1 \mathrm{~h}$ (either clotrimazole or pateamine A to induce SG assembly by different mechanisms). The inhibitory effect on SGs could be seen with as little as 15 min pre-infection. The decrease in SGs observed became more pronounced over time, up to at least $2 \mathrm{~h}$, which was the maximum time examined. Intriguingly, Shigella infection alone and in combination with SG-inducing drugs, still exhibited elevated P-eIF2 $\alpha$. They further examined several Shigella mutants, but were not able to find any that rescued the disruption of SGs. These results suggest that while the virulent wild type Shigella induces SG formation to a limited extent, it, nevertheless, exhibits a mechanism to inhibit SG formation despite elevated P-eIF2 $\alpha$.

Infection of MEF cells with Listeria resulted in an induction of host SGs, which was P-eIF2 $\alpha$ dependent at 1 hpi (Abdel-Nour et al., 2019). However, the level was not sustained at later time points, but, nevertheless, rose again to higher levels at 4-5 hpi. This is suggestive of a possibility of SG oscillation in bacterial cells as has been previously observed during hepatitis $\mathrm{C}$ virus infection (Ruggieri et al., 2012).

Finally, in contrast to bacterial infections, a cell line infected with a protozoan parasite Plasmodium did not result in host SG formation at $1 \mathrm{hpi}$ as assessed by multiple SG marker proteins, including G3BP1, eIF4G, and eIF3ๆ (Hanson and Mair, 2014). Furthermore, extending the infection time up to $24 \mathrm{~h}$, did not reveal SG formation.

Taken together, these results reveal that host SG assembly, when examined, can be a response to microbial infection. In addition, from the handful of microbes investigated, there appears to be mechanisms to limit the extent of SG formation. Nevertheless, a limitation of these studies is that mostly a single 
TABLE 1 | Microbes that induce stress granule (SG) formation.

\begin{tabular}{|c|c|c|c|c|}
\hline Microbe & Marker & Time & Notes & References \\
\hline L. monocytogenes & TIA1 & $1 \mathrm{~h}$ & $10 \%$ to $20 \%$ (4-5 hpi) & Abdel-Nour et al. (2019) \\
\hline S. typhimurium & TIA1 & $0.5 \mathrm{~h}$ & $2 \%$ at $0.5 \mathrm{hpi}$, increase to $5 \%$ at $5 \mathrm{hpi}$ & Abdel-Nour et al. (2019) \\
\hline S. typhimurium & TIA1 & $1 \mathrm{~h}$ & Transient (only 1-2 hpi) & Tattoli et al. (2012) \\
\hline S. flexneri & $\mathrm{TIA} 1$ & $0.5 \mathrm{~h}$ & $5 \%$, to $20-30 \%$ at $3-5$ hpi & Abdel-Nour et al. (2019) \\
\hline S. flexneri & TIA1 & $2 \mathrm{~h}$ & Significant at 2 hpi; Persists until 4 hpi & Tattoli et al. (2012) \\
\hline S. flexneri & elF3b & $2 \mathrm{~h}$ & Invasive Shigella only to about $20 \%$ at 2 hpi & Vonaesch et al. (2016) \\
\hline
\end{tabular}

SG marker protein (TIA1) was used, precluding identification of compositional differences upon infection. For example, SG compositional differences have been often observed in viruses, where non-SG foci can assemble with the SG protein G3BP1 (Eiermann et al., 2020). However, since host eIF2 $\alpha$ phosphorylation is a common outcome of microbial infection, it should be expected that SG assembly is a similarly widespread host response as described below.

\section{eIF2 $\alpha$ PHOSPHORYLATION AND MICROBIAL INFECTION}

The proximal cause of canonical physiological SG assembly is generally phosphorylation of the $\alpha$ subunit of eIF2 (eIF2 $\alpha$ ). eIF2 is a translation initiation factor, that, when bound to GTP brings the initial Met-tRNA ${ }_{i}{ }^{\text {Met }}$ to the ribosomal pre-initiation complex beginning cap-dependent translation in eukaryotes (Adomavicius et al., 2019). After initial AUG recognition, eIF2-GDP is generated through hydrolysis, activated by the GTPase-activating protein eIF5. To facilitate further translation initiation, eIF2-GTP must be re-generated by interaction with its guanine nucleotide exchange factor, eIF2B. Phosphorylation of eIF $2 \alpha$ increases its affinity to eIF2B, which both prevents the GDP:GTP exchange and sequesters eIF2 $\alpha$ in a high-affinity complex (Hershey, 1989). An elevation of P-eIF $2 \alpha$ by $20-30 \%$ has been suggested to be sufficient for sequestration of eIF2B to limit translation initiation, depending on cell type and organism (Brostrom and Brostrom, 1997). These combined effects inhibit translation initiation and promote SG formation.

This review will concentrate on physiologically predominant SGs that are reliant on P-eIF2 $\alpha$ assembly, termed "type I" (Riggs et al., 2020; Hofmann et al., 2021). However, other modes of assembly have been documented with some differences in protein composition: for example, type II SG assembly occurs due to inhibition of eIF4A activity, while type III SGs are induced by nitric oxide, UV, as well as other agents (Hofmann et al., 2021). In addition, there remains an additional class of SGs induced by molecular crowding, for example, by osmotic stress (Bounedjah et al., 2012; Jalihal et al., 2020). These additional cases are significantly less studied compared with the canonical type I SG that is the focus of this review this review.

Phosphorylation of eIF $2 \alpha$ occurs in response to diverse stresses, which cause the pathway activation to be termed the integrated stress response (ISR). The ISR is regulated by four eIF2 $\alpha$ kinases in humans: PKR, PERK, GCN2, and HRI (discussed in their own section below). Activation of these eIF $2 \alpha$ kinases induce phosphorylation of eIF $2 \alpha$ at serine 51 (Figure 1).

Assembly of bona fide SGs due to infection, results from eIF $2 \alpha$ phosphorylation (P-eIF2 $\alpha$ ) with few exceptions as described previously. A useful proxy for the presence of SGs due to infection can be elevated P-eIF $2 \alpha$ or the activation of the kinases that phosphorylate eIF2 $\alpha$. In the absence of data demonstrating SGs during bacterial, fungal, and protozoan infection, the activation of ISR kinases, and/or elevated P-eIF $2 \alpha$ can provide a suggestive view into whether SGs form.

Many studies examining P-eIF2 $\alpha$ levels have identified individual bacterial and fungal proteins, and small molecules that are responsible for the increase in the proportion of P-eIF $2 \alpha$ (Table 2). These molecules also give insight into the mechanism by which microbes are sensed in the host cell. Most prominent among these are the formation of pores in the host membrane, host membrane damage, and reactive oxygen species (ROS). There are also other mechanisms and cases where no mechanism is known, simply that the infection by the microbe itself results in an increase in host P-eIF2 $\alpha$ (Figure 2 and Table 3 ).

It is striking that infection results in elevated P-eIF $2 \alpha$ in most cases examined. It is important to note that in many cases, the direct effect on P-eIF $2 \alpha$ has not been measured, but only inferred from downstream effects on translation. While P-eIF $2 \alpha$ inhibits general translation initiation, it preferentially increases translation of mRNAs containing upstream open reading frames in their 5' UTR by multiple mechanisms (Wek, 2018). Many of these preferentially translated proteins have central roles in the stress response signaled by $\mathrm{P}$-eIF $2 \alpha$, such as GADD34, ATF4, and CHOP, which among other proteins, are typically used as readouts for the ISR (see Figure 1). Their roles in stress are diverse. ATF4 is a transcription factor promoting transcription of genes in the ISR including GADD34 and CHOP. GADD34 is a scaffolding protein that promotes dephosphorylation of P-eIF $2 \alpha$ by targeting the PP1 phosphatase to P-eIF2 $\alpha$, whereas CHOP is a pro-apoptotic transcription factor whose expression is also dependent on ATF6, another ER stressinduced transcription factor.

\section{Gram-Negative Bacteria}

Most studies on host P-eIF2 $\alpha$ levels during infection have been performed on Proteobacteria, a diverse Gram-negative phylum containing a number of human pathogens. Among these bacteria, all studies described here have shown increased host P-eIF $2 \alpha$ in response to infection or metabolites produced by the bacteria in human cells. 


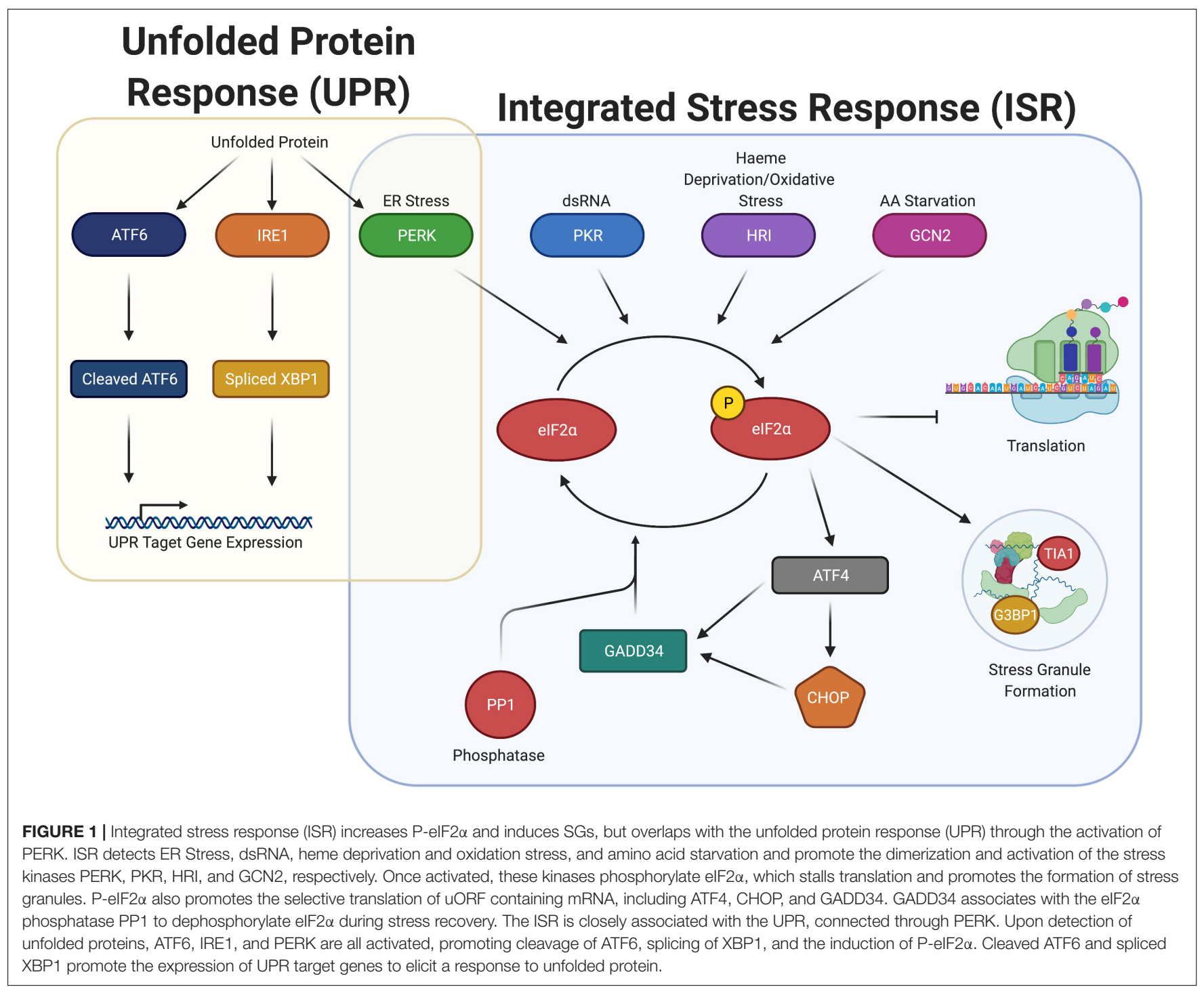

Gammaproteobacteria is the largest class of Proteobacteria and includes Escherichia coli, the most well-studied bacteria of this grouping. The Shiga toxin-producing strain (STEC), capable of causing gastroenteritis in humans, promotes an increase in P-eIF2 $\alpha$ via expression of subtilase cytotoxin (Morinaga et al., 2008; Wolfson et al., 2008). These studies demonstrated increased P-eIF2 $\alpha$ in Vero cells that occurs in response to addition of the toxin. Subtilase is a protease that when internalized, mediates cleavage of the ER chaperone $\mathrm{BiP}$, which is important in monitoring ER stress and results in activation of eIF2 $\alpha$ kinase PERK and induction of CHOP (Figure 1). However, the effect was only seen when subtilase was added to the cells and not that of the infection with the organism itself.

Other gammaproteobacteria elevate host P-eIF2 $\alpha$ through pore-forming toxins (PFTs). For example, exposure to aerolysin PFT from Aeromonas hydrophila in HT29 cells promotes a $\sim$ threefold increase in P-eIF2 $\alpha$ after $3.5 \mathrm{~h}$ (Gonzalez et al., 2011). This is comparable with the VvhA toxin in the gammaproteobacteria Vibrio vulnificus, which induces P-eIF2 $\alpha$ in Caco-2 cells to nearly threefold after $6 \mathrm{~h}$ of exposure (Song et al., 2016). In addition, similar to the STEC bacteria, the expression of CHOP and ATF4 was also increased.

Primary cells were also shown to activate the ISR when exposed to microbial toxins. Primary bronchial epithelial cells incubated with cultured media from the Gammaproteobacteria Pseudomonas aeruginosa PAO1 strain resulted in a twofold increase in P-eIF2 $\alpha$ after $4 \mathrm{~h}$ of exposure (van 't Wout et al., 2015). Further investigation identified two toxins as sufficient for the increase: the alkaline protease AprA that can affect protein translocation in the ER and pyocyanin, which generates ROS in host cells.

A number of other gammaproteobacteria show similar upregulation of P-eIF2 $\alpha$ in host cells upon infection. Elevated P-eIF2 $\alpha$ was reported for Yersinia pseudotuberculosis infection of the mouse macrophage-like RAW 264.7 cells (Shrestha et al., 2012). This study further investigated downstream gene expression and determined that an ATF4 reporter was induced 
TABLE 2 | Microbial molecules that increase elF2 $\alpha$ phosphorylation.

\begin{tabular}{|c|c|c|c|}
\hline Mechanisms & Microbe (Compound) & Type & References \\
\hline \multirow[t]{6}{*}{ Pore forming protein } & Aeromonas hydrophila (PA) & Gram (-) & Gonzalez et al. (2011) \\
\hline & E. coli (hemolysin A) & Gram (-) & Kloft et al. (2010) \\
\hline & Vibrio cholerae (VCC cytolysin) & Gram (-) & Kloft et al. (2010) \\
\hline & Listeria monocytogenes (Listeriolysin O) & Gram (+) & Gonzalez et al. (2011); Pillich et al. (2012); Tattoli et al. (2013) \\
\hline & Staphylococcus aureus ( $\alpha$-toxin) & Gram (+) & Kloft et al. (2010); von Hoven et al. (2012) \\
\hline & Streptococcus pyogenes (Streptolysin O) & Gram (+) & Kloft et al. (2010) \\
\hline \multirow[t]{3}{*}{ Membrane damage } & $\begin{array}{l}\text { Salmonella typhimurium (Type III secretion } \\
\text { system) }\end{array}$ & Gram (-) & Kloft et al. (2010); Vonaesch et al. (2016) \\
\hline & Shigella flexneri (Unknown) & Gram (-) & Tattoli et al. (2012) \\
\hline & $\begin{array}{l}\text { Mycobacterium tuberculosis (ESAT-6, } \\
\text { membrane lysis) }\end{array}$ & Mycobacteria & Choi et al. (2010) \\
\hline \multirow[t]{4}{*}{ ROS/ROS generation } & $\begin{array}{l}\text { Mycobacterium tuberculosis (Heparin-Binding } \\
\text { Hemagglutinin Adhesin-HBHA) }\end{array}$ & Mycobacteria & Choi et al. (2013) \\
\hline & Mycobacterium tuberculosis (38-kDa antigen) & Mycobacteria & Lim et al. (2015) \\
\hline & Pseudomonas aeruginosa (Pyocyanin) & Gram (-) & Yang et al. (2016) \\
\hline & $\begin{array}{l}\text { Streptococcus pneumoniae (Pneumococcal } \\
\mathrm{H}_{2} \mathrm{O}_{2} \text { ) }\end{array}$ & Gram (+) & Loose et al. (2015) \\
\hline ER stress through BiP cleavage & Shiga toxigenic E. coli (Subtilase cytotoxin) & Gram (-) & Morinaga et al. (2008); Wolfson et al. (2008) \\
\hline \multirow[t]{3}{*}{ Other mechanisms } & $\begin{array}{l}\text { Pseudomonas aeruginosa (Homoserine } \\
\text { lactose-HSL-C12) }\end{array}$ & Gram (-) & von Hoven et al. (2012); Grabiner et al. (2014) \\
\hline & Chlamydia trachomatis (pORF5) & Gram (-) & Wen et al. (2020) \\
\hline & $\begin{array}{l}\text { Histoplasma capsulatum (Calcium binding } \\
\text { protein Cbp1) }\end{array}$ & Fungi & English et al. (2017) \\
\hline
\end{tabular}

in HEK293 cells infected with Y. pseudotuberculosis, along with a similar expression in RAW 264.7 cells (Shrestha et al., 2012).

Shigella flexneri illustrates a clear role of infection in elevated host P-eIF2 $\alpha$. HeLa cells exhibit increased P-eIF2 $\alpha$ levels at 12 hpi (Tattoli et al., 2012; Vonaesch et al., 2016; Abdel-Nour et al., 2019). Nevertheless, within 4 hpi, P-eIF2 $\alpha$ returns to near uninfected levels (Tattoli et al., 2012). These data suggest that S. flexneri may possess a mechanism to temper this response, possibly via the GADD34 protein that regulates PP1 phosphatase to target P-eIF2 $\alpha$.

While P-eIF $2 \alpha$ levels were not investigated for the closely related bacteria, Salmonella typhimurium, they are likely to be elevated in host cells during its infection as well. Evidence for elevated P-eIF $2 \alpha$ includes activation of an upstream P-eIF $2 \alpha$ kinase, along with downstream gene induction, and even the formation of SGs in HeLa cells upon infection, which largely occurs via the P-eIF2 $\alpha$ pathway (Tattoli et al., 2012).

Another example in Proteobacteria is Campylobacter jejuni, an epsilonproteobacteria, which has a near threefold increase in P-eIF $2 \alpha$ after $12 \mathrm{~h}$ of infection in Caco- 2 cells when compared with uninfected cells (Tentaku et al., 2018).

Finally, elevated P-eIF2 $\alpha$ was observed in the Gram-negative bacteria Chlamydia pneumonia and Chlamydia trachomatis infection. As an obligate intracellular bacteria, the infection of a host cell and bacterial replication occur differently in Chlamydia compared with the other bacteria described here (Moulder, 1991; Hanada et al., 2003; Mpiga and Ravaoarinoro, 2006). They exhibit a biphasic developmental cycle, in which they produce small elementary bodies (EBs) which are extracellular, infectious, metabolically inactive, and non-dividing. Once infecting a cell, EBs can differentiate into much larger intracellular reticulate bodies (RBs) that can divide and multiply within membrane-limited chlamydial inclusions. The replicating $\mathrm{RBs}$ can be transformed into EBs to be distributed upon host cell lysis.

Chlamydial productive infection results in lysis within 4872 hpi. However, during bacterial stress and in certain serovars, a persistent form of infection can occur that has low infectivity, retaining the RB form of Chlamydia (Moulder, 1991; Hanada et al., 2003; Mpiga and Ravaoarinoro, 2006). These infections show a similar response with P-eIF2 $\alpha$ in host cells as to the other bacteria described above. C. pneumonia was shown to induce P-eIF2 $\alpha$ nearly twofold in HEp-2 cells after $2 \mathrm{~h}$ of persistent infection (Shima et al., 2015), while C. trachomatis promoted P-eIF $2 \alpha$ to a similar fold increase at 12,24 , and $40 \mathrm{~h}$ post persistent infection in HeLa cells along with the corresponding upregulation of the downstream genes, ATF4 and CHOP (Wen et al., 2020). In contrast, a lymphogranuloma venereum serovar that causes a productive, invasive infection did not cause elevated P-eIF2 $\alpha$ at 2.5 hpi (Böhme et al., 2010).

Simkania negevensis is an obligate intracellular bacteria, closely related to C. trachomatis and C. pneumonia, that causes no significant changes in P-eIF $2 \alpha$ in response to its infection at 48 hpi (Mehlitz et al., 2014). However, as noted above, P-eIF2 $\alpha$ elevation may be transient during infection, and thus potentially only noticeable earlier in infection. Interestingly, $S$. negevensis also inhibited P-eIF $2 \alpha$ production from druginduced ER stress by thapsigargin; therefore, it is possible that this bacteria may be capable of directly preventing increased P-eIF $2 \alpha$ levels early in infection. 


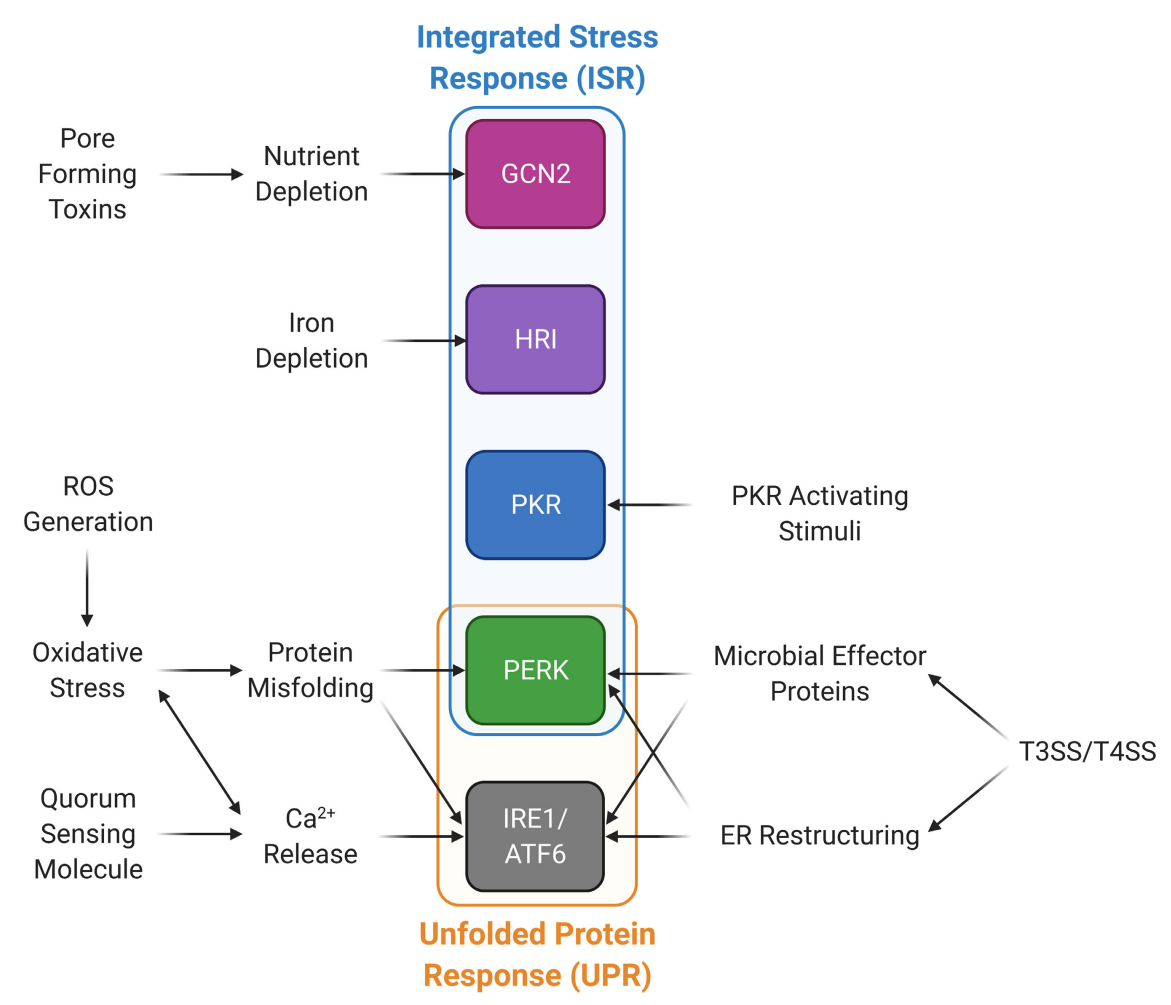

FIGURE 2 | Microbial stimuli activate stress kinases in the integrated stress response (ISR) and the unfolded protein response (UPR) pathways. Microorganisms are able to induce the ISR and UPR through a variety of mechanisms. Type III and IV bacterial secretion systems (T3SS and T4SS) promote ER restructuring and the release of microbial effector proteins that can activate PERK and the UPR. PKR can be activated through PKR activating stimuli other than dsRNA. Calcium can be released through quorum sensing molecules and ROS generation, which also induces oxidative stress and protein misfolding, in turn activating the UPR and PERK. Nutrient and iron deprivation may be induced by microbes and their products promoting activation of GCN2 and HRI, respectively.

\section{Gram-Positive Bacteria}

Infection of Gram-positive bacteria similarly elevates P-eIF2 $\alpha$ as seen in Gram-negative bacteria; however, these species have been examined to a more limited extent. The species examined for this effect are all members of the Firmicutes phylum, either Bacilli (Listeria monocytogenes, Streptococcus pneumoniae, and Staphylococcus aureus) or Clostridia (Clostridium difficile).

Listeria monocytogenes, a pathogenic rod-shaped bacterium, is one of the most well-studied Gram-positive bacterium with regard to P-eIF2 $\alpha$. L. monocytogenes can actively penetrate host cell membranes and is the most common cause of listeriosis, a disease that can lead to severe illness and even death. Elevated P-eIF2 $\alpha$ in cultured cells has been observed with L. monocytogenes from both infection and exposure to Listeria-specific toxins. In mouse cells, infection with $L$. monocytogenes resulted in both elevated P-eIF2 $\alpha$ and expression of the downstream P-eIF $\alpha \alpha$-regulated genes (Shrestha et al., 2012). An investigation of $L$. monocytogenes infection also demonstrated that P-eIF2 $\alpha$ increases after bacterial infection in the P388D1 mouse macrophage cell line (Pillich et al., 2012). Similarly, an increase in P-eIF2 $\alpha$ was observed in HeLa cells infected with L. monocytogenes between 0.5 and $2 \mathrm{~h}$, with a decrease to near basal uninfected levels after $3 \mathrm{~h}$ (Tattoli et al., 2013).
Listeriolysin O (LLO), a pore-forming toxin (PFT) produced by L. monocytogenes, is sufficient for the increase in P-eIF $2 \alpha$ levels in P388D1 and HT29 cells after 1 and $2 \mathrm{~h}$, respectively (Gonzalez et al., 2011; Pillich et al., 2012). Supporting these results, was the absence of a significant increase in P-eIF2 $\alpha$ when infected with a L. monocytogenes strain lacking the gene encoding for LLO (Pillich et al., 2012; Besic et al., 2020).

Another PFT was the causative agent for increased P-eIF2 $\alpha$ in the bacillus Staphylococcus aureus (Kloft et al., 2010). S. aureus is commonly found in skin flora and associated with a number of human diseases. It was shown to elevate P-eIF $2 \alpha$ levels by exposure to the pore-forming $\alpha$-toxin in as little as $40 \mathrm{~min}$ in HaCaT cells (Kloft et al., 2010).

In contrast with the other Firmicutes, a PFT from the bacillus Streptococcus pneumoniae does not elevate P-eIF2 $\alpha$ (Table 3 ). The amount of P-eIF $2 \alpha$ increased in H441 cells upon incubation with S. pneumoniae supernatant and at $3 \mathrm{hpi}$ (Loose et al., 2015). This effect was abrogated by addition of catalase to the supernatant as well as in an infection with a bacterial mutant deficient in hydrogen peroxide production, suggestive of being caused by streptococcal hydrogen peroxide.

Finally, Clostridium difficile, which is a more distantly related Gram-positive rod-shaped Firmicutes that causes antibiotic-related gastrointestinal illnesses, was shown to 
TABLE 3 | Microbial infections or compounds that affect elF2 $\alpha$ phosphorylation.

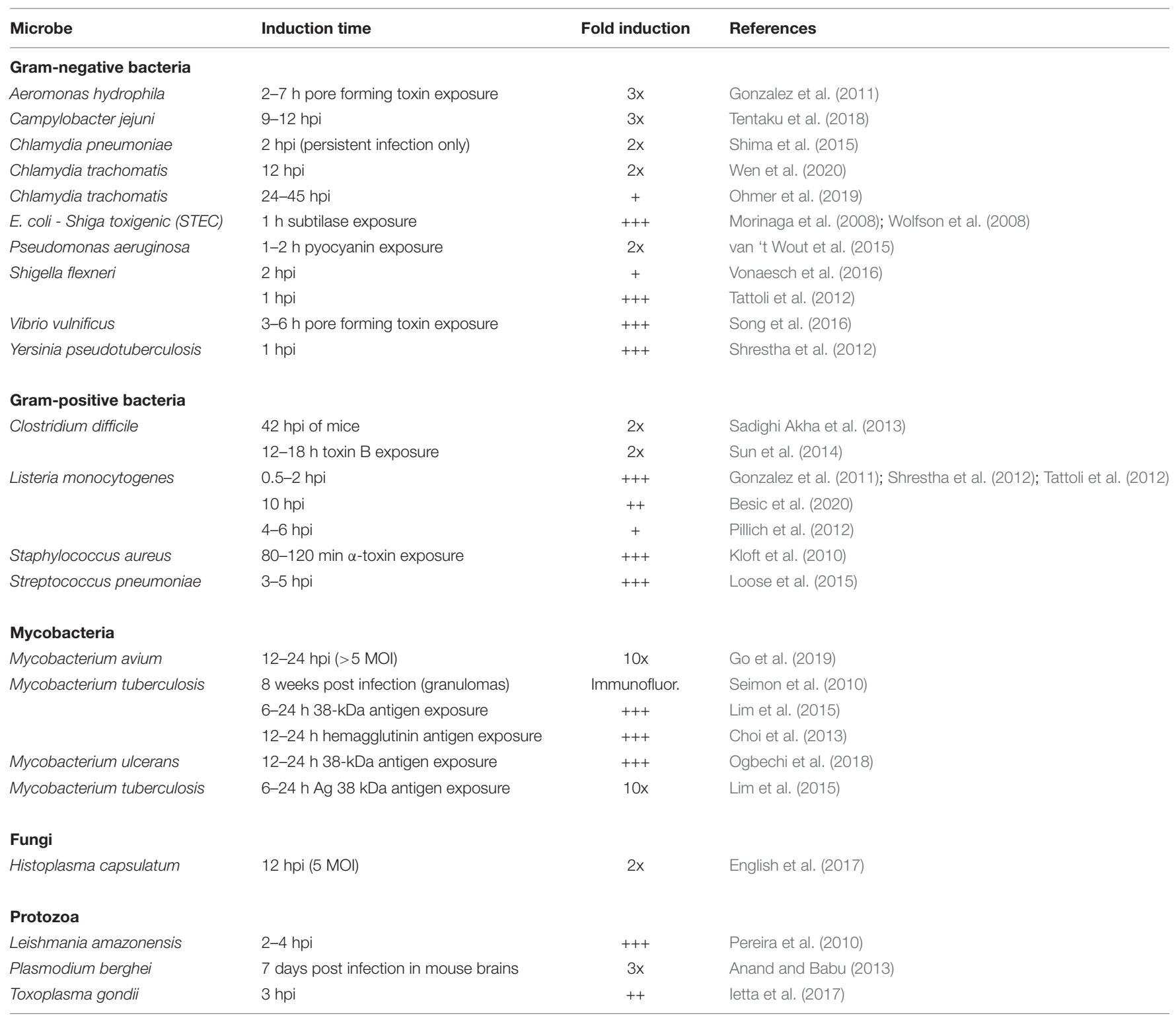

Reduction in elF $2 \alpha$ phosphorylation

\begin{tabular}{|c|c|c|c|}
\hline Microbe & Induction time & Fold reduction & References \\
\hline \multicolumn{4}{|l|}{ Gram-negative bacteria } \\
\hline Simkania negevensis & 3 days post infection & $-10 x$ & Mehlitz et al. (2014 \\
\hline \multicolumn{4}{|l|}{ Other bacteria } \\
\hline Mycobacterium tuberculosis & 6-24 hpi & $-/-$ & Lim et al. (2011) \\
\hline Mycoplasma hyopneumoniae & 6-24 hpi & - & Pan et al. (2020) \\
\hline
\end{tabular}

,,++++++ are subjective indications of increased $P$-elF2 $\alpha$ due to absence of quantification in study $(\sim 2 x, \sim 4 x, \sim 10 x),-,-$ are subjective indications of decreased $P$-elF2 $\alpha$. PFT, pore-forming toxin.

induce elevated P-eIF2 $\alpha$ in infected mouse cells, along with increased downstream GADD34 expression (Sadighi Akha et al., 2013). Furthermore, it was found that the secreted Clostridium toxin B, which also disrupts host intracellular signaling and cell structure, induced P-eIF2 $\alpha$ in mouse CT26 cells, along with increased expression of the downstream genes ATF4 and CHOP as well as ATF6, which belongs to the UPR (Sun et al., 2014). 


\section{Mycobacteria and Other Bacteria}

Mycobacterium, which falls within the Gram-positive phylum Actinobacteria, is characterized by "acid fastness" which prevents Gram-positive staining due to the lipids attached to the cell wall. However, Mycobacterium appears to be no different in their ability to induce P-eIF2 $\alpha$ in host cells.

Mycobacterium avium, a human pathogen that can cause severe illness in immunocompromised patients (Kiehn et al., 1985), showed an increase in P-eIF2 $\alpha$ between 12 and 24 hpi in RAW 264.7 cells (Go et al., 2019). They also showed an induction of the upstream activating kinase PERK prior to the increase in eIF2 $\alpha$ phosphorylation, along with increased downstream CHOP expression coinciding with elevated P-eIF $2 \alpha$.

Mycobacterium ulcerans, capable of causing Buruli ulcer, produces the toxin mycolactone, which was shown to induce P-eIF2 $\alpha$ when exposed to HeLa cells, along with increased CHOP and ATF4 protein expression (Ogbechi et al., 2018).

Mycobacterium tuberculosis, likely the most infamous Mycobacterium due to being the causative agent of tuberculosis, is one organism that appears to both increase and decrease P-eIF2 $\alpha$ (Table 3). One study showed that RAW 264.7 cells infected with M. tuberculosis inhibited P-eIF2 $\alpha$ at $24 \mathrm{hpi}$, but also observed significant expression of the P-eIF2 $\alpha$ downstream gene CHOP at this time point (Lim et al., 2011). The study further found that two M. tuberculosis virulence factors, the $38-\mathrm{kDa}$ antigen and the heparin-binding hemagglutinin antigen (HBHA), were capable of inducing P-eIF2 $\alpha$ and downstream CHOP protein expression in both BMDM and RAW 264.7 cells (Choi et al., 2013; Lim et al., 2015). This is interesting, as it would suggest that certain molecules expressed by $M$. tuberculosis promote elevated P-eIF2 $\alpha$, while others counteract this response. Finally, in granulomas of M. tuberculosis-infected mice, increased P-eIF2 $\alpha$ was detected along with increased gene expression in P-eIF2 $\alpha$ downstream genes (Seimon et al., 2010).

Taken together, these results demonstrate that Mycobacteria may have an adaptation to reduce elevated P-eIF2 $\alpha$ after infection. While reduction of P-eIF2 $\alpha$ in M. tuberculosis-infected cells commenced at $24-36 \mathrm{~h}$, it was not reported for M. avium. However, it is possible that extended infection could also result in $\mathrm{P}$-eIF2 $\alpha$ reduction in this case as well.

Finally, the unrelated bacteria Mycoplasma hyopneumoniae, which has the unusual characteristic of lacking a cell wall, has shown a similar effect on P-eIF2 $\alpha$ (Pan et al., 2020). This study showed a decrease in the P-eIF $2 \alpha$ to $20 \%$ of the total eIF $2 \alpha$ after $36 \mathrm{~h}$, along with a decrease in ATF4 mRNA levels over the same time frame.

\section{Eukaryotic Microbial Infections}

Elevated P-eIF2 $\alpha$ has also been observed in fungal and protozoan infection. However, very few eukaryotic organisms have been investigated for elevated P-eIF2 $\alpha$ upon infection, limited to three protozoan species (Leishmania amazonensis, Plasmodium berghei, and Toxoplasma gondii) and one fungal species (Histoplasma capsulatum).

The three protozoan species all demonstrated an increase in P-eIF2 $\alpha$ upon infection of both mice and cultured cells.
First, Leishmania amazonensis, a trypanosome that causes leishmaniasis, was shown to induce P-eIF2 $\alpha$ in THP-1 cells, along with PKR phosphorylation from 2 to 4 hpi (Pereira et al., 2010). Second, Plasmodium berghei, a protozoan parasite, which causes malaria in rodents, was found to cause elevated P-eIF2 $\alpha$ in mouse brains 7 days after intraperitoneal infection (Anand and Babu, 2013). Third, Toxoplasma gondii, a protozoan parasite that can cause toxoplasmosis in humans, was shown upon infection of BeWo cells to cause a near fourfold increase in P-eIF $2 \alpha$ compared with uninfected cells 24-48 hpi (Ietta et al., 2017).

Histoplasma capsulatum, which causes the disease histoplasmosis is the lone fungal pathogen examined for P-eIF2 $\alpha$ levels. This fungus promotes P-eIF2 $\alpha$ increases in infected macrophages 12 hpi to a similar extent to that caused by tunicamycin treatment (English et al., 2017). This study also found elevation of downstream ATF4 protein and CHOP mRNA expression in the first $24 \mathrm{~h}$ of lytic infection (English et al., 2017).

\section{Adaptation to Microbial Infections}

The vast majority of microbial infections examined result in elevated host P-eIF2 $\alpha$. However, at least four species are exceptions to this outcome. Since P-eIF2 $\alpha$ has not been extensively examined during microbial infection, these outliers may represent common adaptations of either the host or microbe. These examples fall into three categories: return to basal uninfected P-eIF2 $\alpha$ levels, no increase in P-eIF2 $\alpha$, or a decrease in P-eIF2 $\alpha$.

First, a transient increase in P-eIF2 $\alpha$ with return to basal levels was observed in both Gram-positive and Gram-negative bacteria. For example, in the Gram-positive bacteria Listeria monocytogenes, a transient increase in P-eIF2 $\alpha$ was observed after $30 \mathrm{~min}$, returning to near basal uninfected levels after $3 \mathrm{~h}$ (Tattoli et al., 2013). This also occurred within 3-4 h after Shigella infection (Tattoli et al., 2012), $7 \mathrm{~h}$ after Aeromonas infection (Gonzalez et al., 2011), and after 2-4 h of shiga toxigenic E. coli infection (Morinaga et al., 2008; Wolfson et al., 2008).

Second, no increase in P-eIF2 $\alpha$ was observed upon infection with the Gram-negative bacteria, Simkania negevensis, when examined at 3 hpi (Mehlitz et al., 2014).

Finally, the mycobacterial species $M$. tuberculosis and Mycoplasma species M. hyopneumoniae, both reduced the level of P-eIF2 $\alpha$ at 24-36 hpi (Lim et al., 2011; Pan et al., 2020).

Taken together, these examples may represent unique microbial adaptation strategies to limit elevated host P-eIF2 $\alpha$. However, it is possible that most microbial infections cause a return to uninfected host P-eIF2 $\alpha$ levels as the infection progresses and can even lower the P-eIF2 $\alpha$ below that of uninfected levels as seen in mycobacteria. More study with longer time-courses will be necessary to resolve this issue in the future.

\section{ACTIVATION OF THE INTEGRATED STRESS RESPONSE UPON MICROBIAL INFECTION}

In mammals, multiple cellular stresses are sensed by four eIF $2 \alpha$ kinases (Pakos-Zebrucka et al., 2016). Activation of an eIF2 $\alpha$ 
kinase can provide clues to the type of stress that is occurring in the infected cells. The common stresses that are known to induce P-eIF $2 \alpha$ during infection are ER stress and amino acid starvation (Celli and Tsolis, 2015; Abdel-Nour et al., 2019). These are primarily sensed by two different eIF2 $\alpha$ kinases: PERK (PKRlike endoplasmic reticulum kinase/EIF2AK3) and GCN2 (general control non-derepressible 2/EIF2AK4). The other two eIF2 $\alpha$ kinases are: HRI (heme-regulated inhibitor/EIF2AK1) and PKR (double-stranded RNA-activated protein kinase R/EIF2AK2).

Specific cellular stresses will activate these kinases, although there is considerable overlap resulting in activation of multiple kinases (Figure 2). HRI is activated by heme deprivation in erythrocytes as well as arsenite-induced oxidative stress, heat shock, and osmotic stress in other cells (Burwick and Aktas, 2017). PKR is most commonly induced by viral infection as it is activated by double-stranded RNA, which is often present as a result of viral replication (García et al., 2006). A diverse set of other stresses also can activate PKR as well. Activation of PERK by ER stress with its most welldefined mechanism being dissociation of the Hsp70 protein BiP/GRP78 due to unfolded proteins (Kopp et al., 2019). Finally, GCN2, which is the most widely conserved kinase, found from yeast to humans, is activated during amino acid starvation by detection of deacylated tRNA (Masson, 2019). In microbial infection, these kinases can be activated by either intracellular microbial infection, or extracellular microbes, presumably from molecules produced by the microbe in question (Table 4).

An additional stress on the host cell is from the bacterial type III and type IV secretion systems (T3SS, T4SS). These are two examples of mechanisms employed by bacteria to secrete proteins and DNA into host cells aiding infection. T3SS is found in a number of Gram-negative bacteria, including, S. typhimurium (Coburn et al., 2007), while T4SS is found in both Gram-negative and Gram-positive bacteria (Grohmann et al., 2018). Each system employs a similar, yet distinct method to permeabilize the host cell membrane that may lead to the induction of a stress response. These systems can also lead to activation of the eIF $2 \alpha$ kinases PERK, GCN2, and HRI as described below.

\section{PERK and the Unfolded Protein Response}

Endoplasmic reticulum stress during infection can manifest in several manners, but is generally activated by unfolded proteins and insufficient protein-folding capacity in ER, which induces the unfolded protein response (UPR). In microbial infection, the source of unfolded proteins or ER stress itself is often linked to organisms that can live intracellularly, in close association with ER (Celli and Tsolis, 2015).

The UPR is a three-pronged system (Figure 1), composed of ATF6, IRE1, and PERK (Walter and Ron, 2011). When the UPR is activated, the active forms of ATF6 and IRE1 assist the cell in combating ER stress. In this situation, ATF6 is cleaved and promotes transcription of genes to enhance protein folding capacity, while IRE1 is a kinase that engages in non-conventional splicing of the mRNA encoding for the XBP1 transcription factor. When spliced, $\mathrm{XBP} 1 \mathrm{mRNA}$ is translated into its active form, that drives transcription of genes facilitating ER expansion. Finally, PERK, as described above, phosphorylates eIF2 $\alpha$. Increased P-eIF $2 \alpha$ inhibits translation initiation, thus reducing the load on the ER.

In addition to general inhibition of initiation, P-eIF $2 \alpha$ promotes preferential translation of ATF4. ATF4, in turn, leads to transcription of $\mathrm{CHOP}$ mRNA, that itself promotes both transcription of apoptosis-related genes and the phosphataseinteracting protein GADD34 (Figure 1). GADD34 complexes with the catalytic subunit of the PP1 phosphatase (PP1c) to promote its activity, reducing P-eIF $2 \alpha$, maintaining a lower level of P-eIF $2 \alpha$ as high P-eIF $2 \alpha$ levels can promote apoptosis. The reduction in P-eIF2 $\alpha$ can thus allow protection of the cell from ER stress, while avoiding apoptosis (Walter and Ron, 2011). A number of microbial pathogens induce PERK activation in host cells, either exclusively or alongside the UPR. Therefore, the consequences of infection can be due to P-eIF2 $\alpha$ from PERK activation or dependent on the two other branches of the UPR (ATF6 and IRE1).

During microbial infection, the activation of PERK is caused by a variety of mechanisms (Table 4). The two most prominent of these are calcium release from the ER and oxidative stress. There are also other mechanisms, such as $\mathrm{BiP}$ cleavage and those that activate PERK by an unknown means.

First, several microbes activate PERK through calcium release from the ER. Calcium release activates ER stress through disruption of $\mathrm{Ca}^{2+}$ homeostasis, as many ER chaperones require calcium to function (Schröder, 2008). A likely explanation for the activation of PERK by the Gram-negative bacteria Pseudomonas aeruginosa is through the calcium release triggered by the secretion of its quorum-sensing molecule, $\mathrm{N}$-(3-oxododecanoyl)homoserine lactone (HSL-C12) (Grabiner et al., 2014). HSLC12 likely acts on PERK, as P-eIF2 $\alpha$ levels are greater in cells containing PERK than in $\mathrm{PERK}^{-/-}$cells. Nevertheless, some residual elevated P-eIF2 $\alpha$ was observed in PERK ${ }^{-/}$cells, suggestive of involvement of other eIF $2 \alpha$ kinases. Another study found that GADD34 and CHOP expression were induced in infected cells, but this induction was tapered by the knockdown of HRI (van 't Wout et al., 2015). Furthermore, P. aeruginosa infection was shown to induce P-eIF2 $\alpha$ in host cells via GCN2 (Yang et al., 2016). These reports implicate $P$. aeruginosa in activation of multiple kinases upon infection, resulting in elevated P-eIF2 $\alpha$.

The Gram-negative bacteria Campylobacter jejuni is another example of increased P-eIF2 $\alpha$ and PERK activation upon infection, presumably by $\mathrm{Ca}^{2+}$ release (Hu et al., 2005; Tentaku et al., 2018). However, in contrast, this does not appear to activate the other UPR-associated responses, such as splicing of XBP1 and cleavage of ATF6 (Tentaku et al., 2018).

Release of $\mathrm{Ca}^{2+}$ was also implicated in stress induced by the shiga toxin Stx1 from Shigella dysenteriae in THP-1 cells (Lee et al., 2008). Stx1 was shown to induce the ER stress response through all three branches of the UPR: PERK, IRE1, and ATF6 (Lee et al., 2008). 
TABLE 4 | Activation of elF2 $\alpha$ kinases by microbes.

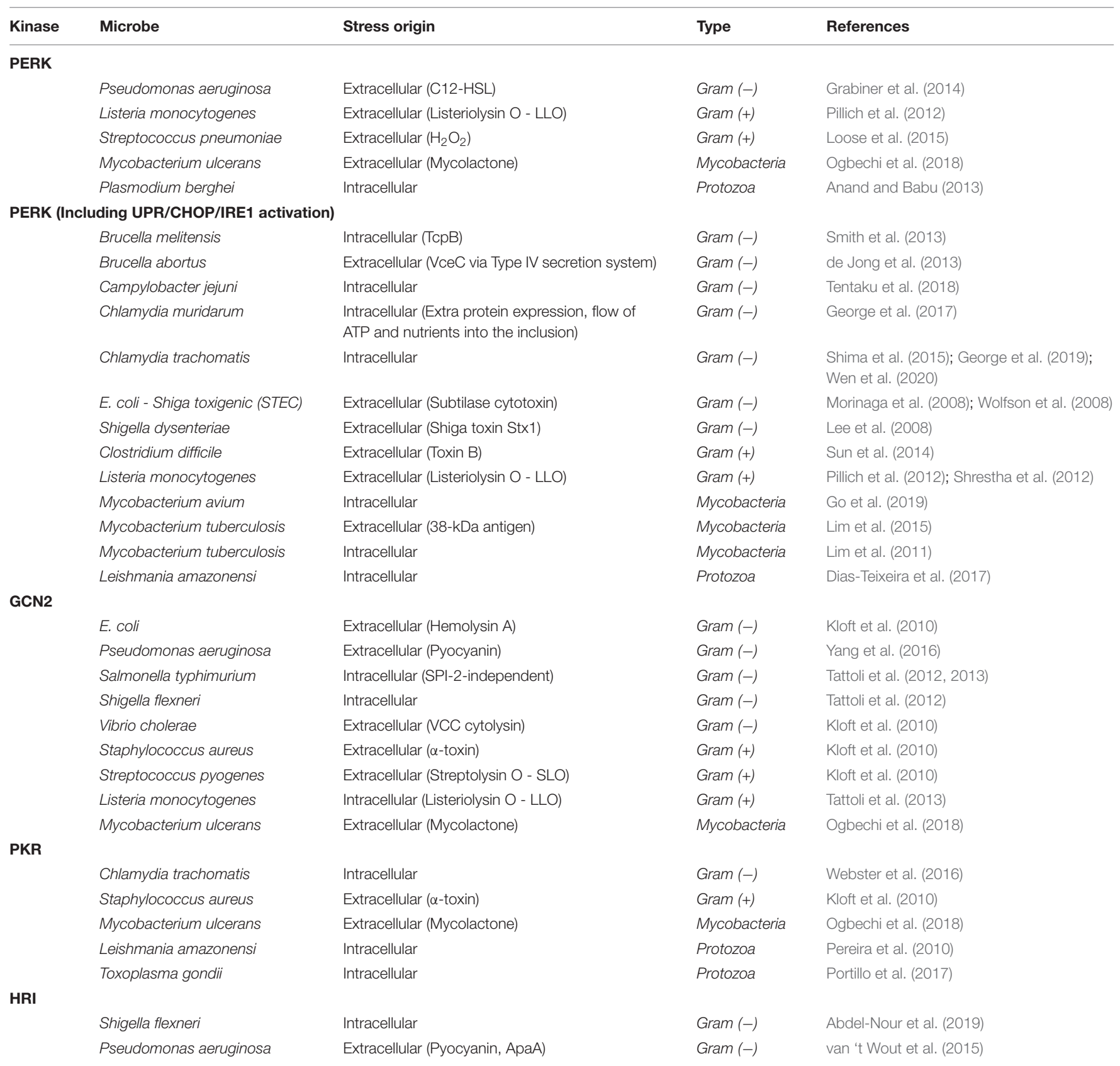

Extracellular may refer to microbial compound alone or extracellular microbes.

The mechanism of UPR activation by the Gram-positive L. monocytogenes is additionally likely due to dysregulation of $\mathrm{Ca}^{2+}$ levels, which induces ER stress-specific apoptosis in host cells along with P-eIF2 $\alpha$ (Pillich et al., 2012). Although not directly investigated, these results suggest PERK activation via UPR leads to increased P-eIF2 $\alpha$ through the production of listeriolysin O (LLO). LLO modulates cellular $\mathrm{Ca}^{2+}$ levels, which might lead to dysregulation of $\mathrm{ER} \mathrm{Ca}^{2+}$ homeostasis (Gekara et al., 2008). Similarly, sublytic levels of LLO can create pores in the plasma membrane, which also results in $\mathrm{Ca}^{2+}$ influx (Repp et al., 2002).
Second, oxidative stress can induce protein misfolding and thus activate the UPR and ER stress/PERK (Zhang and Kaufman, 2008). The Gram-positive bacteria, Streptococcus pneumonia, induced activation of PERK and P-eIF2 $\alpha$ via ER stress caused by pneumococcal $\mathrm{H}_{2} \mathrm{O}_{2}$ (Loose et al., 2015). Since ATF6 and IRE1 activation were not observed, it is likely that the UPR was not activated; rather, it was the ISR alone.

Oxidative stress could be the source of ER stress induced by toxin $\mathrm{B}$, an exotoxin produced by Clostridium difficile. The toxin was shown to cause ER stress, detected through the activation of IRE1 and BiP, along with induction of PERK, ATF4, and CHOP 
mRNA (Sun et al., 2014). The mechanism by which the toxin induces ER stress remains unclear, however, more recent work links it to ROS generation (Frädrich et al., 2016).

ER stress via ROS generation may also occur in Vibrio vulnificus infection. This bacteria expresses the virulence factor $\mathrm{VvhA}$, which is a pore-forming toxin shown to induce P-eIF $2 \alpha$ and CHOP expression. It remains unclear as to which kinase is activated in order to induce P-eIF2 $\alpha$; however, the production of reactive oxygen species by VvhA was found to play a key role (Song et al., 2016).

Generation of ER stress by ROS was also observed in several mycobacterial species. For example, Mycobacterium avium, increases activation of IRE1, ATF6, and PERK following infection of host cells (Go et al., 2019). This study suggested that ER stress was caused by M. avium induced ROS, which is also likely to play a role in the suppression of the M. avium infection.

Similarly, Mycobacterium tuberculosis induced ER stress in host cells detected through the upregulation of BiP, CHOP, P-eIF2 $\alpha$, and spliced XBP1 (Lim et al., 2011, 2015). The former study suggested that live $M$. tuberculosis could cause ER stress by ROS and nitric oxide production in RAW264.7 cells. While the later study suggested that the $38-\mathrm{kDa}$ antigen produced by M. tuberculosis specifically increased ER stress and downstream signaling through apoptosis-induced activation of Toll-like receptor $2 / 4$. In this study, it was undetermined as to which kinase was activated in response to $M$. tuberculosis infection; however, as with a similar organism, it is likely that this ER stress at least induces PERK activation, if not additional kinases.

In addition, Mycobacterium ulcerans produces the virulence factor mycolactone, which was shown to induce P-eIF2 $\alpha$ through the activation of PERK, GCN2, and PKR (Ogbechi et al., 2018). Mycolactone produces ROS in primary keratinocytes, which is suggestive of it inducing PERK as seen for the other mycobacteria (Grönberg et al., 2010). This microbial exotoxin, however, does not induce all branches of the UPR, since IRE1 and ATF6 were not activated (Ogbechi et al., 2018).

Third, BiP cleavage can be a source of PERK/UPR activation in microbial infection. This is exemplified by the shiga toxinproducing E. coli (STEC) that expresses the subtilase cytotoxin. Subtilase promotes ER stress detected through the cleavage of BiP (Morinaga et al., 2008). Similarly, addition of subtilase to Vero cells promoted the phosphorylation of PERK and eIF $2 \alpha$, stalling protein synthesis, albeit transiently (Wolfson et al., 2008). They also found that this stress induced the other arms of the UPR (IRE1 and ATF6).

Other mechanisms are demonstrated by the obligate intracellular pathogen Chlamydia muridarum, which was shown to induce phosphorylation of PERK and the activation of the other two UPR branches in host cells (IRE1 and ATF6) at $48 \mathrm{hpi}$ (George et al., 2017). This UPR response was thought to be caused by the expression of additional proteins in the ER (i.e., Chlamydia early genes), flow of ATP and nutrients into the chlamydial inclusion or by binding to BiP.

Furthermore, Chlamydia, specifically C. trachomatis and C. pneumonia, have been shown to activate the UPR through microbial effector protein interaction with the ER (Shima et al., 2015; George et al., 2019). It was shown that Chlamydia induces this response through the type III secretion system (T3SS), which facilitates transfer of a number of effector proteins that modify the host cytoskeleton (George et al., 2019). Following this, the C. trachomatis protein pORF5 activated PERK, along with UPR-associated proteins, and P-eIF2 $\alpha$, suggesting that both the UPR and ISR are activated upon Chlamydia infection (Wen et al., 2020). Furthermore, it was also determined that ER stress induced by Chlamydia infection promoted PKR activation via the Toll-like receptor signaling, possible due to IRE1dependent host degradation activating PKR alongside PERK (Webster et al., 2016).

An alternative mechanism that induces the UPR is found upon infection with the Gram-negative facultative intracellular pathogen Brucella melitensis. The bacteria fuses with the ER upon infection, in order to facilitate replication; however, this promotes ER restructuring and induces the ER stress response (Smith et al., 2013). Similarly, infection with B. melitensis activated ISR-independent branches of the UPR as shown by upregulated expression of $\mathrm{BiP}, \mathrm{CHOP}$, and increased splicing of XBP1. The increased expression of CHOP suggests that P-eIF $2 \alpha$ is also induced; however, it remains unclear as to which kinase is activated upon infection, although as with the previous microbial infections, it is likely that the UPR and ER stress are tightly associated with PERK activation.

Brucella abortus, which expresses the protein VceC, a type IV secretion system (T4SS) substrate, was shown to induce XBP1 splicing, and interact directly with BiP (de Jong et al., 2013). This would suggest that the UPR is activated upon infection, promoted by ER stress, along with activation of PERK and elevated P-eIF $2 \alpha$, however, this remains to be determined.

Finally, activation of PERK was found after infection with the protozoan parasite Plasmodium berghei. This organism was shown to induce PERK activation, along with IRE1 phosphorylation and ATF6 cleavage, in a mouse model (Anand and Babu, 2013). Additionally, eIF2 $\alpha$ was also activated upon $P$. berghei infection along with induction of ATF4 and GADD34. Taken together, these results suggest that both the UPR and ISR were activated through ER stress.

\section{Protein Kinase R}

PKR activation is commonly caused by viral infection, as dsRNA triggers PKR trans-autophosphorylation forming an active dimer, which can in turn phosphorylate eIF2 $\alpha$. PKR may also be activated by its activating protein, PACT (protein activator of the interferon-induced protein kinase). However, PKR activation by non-viral microbes, would suggest a novel mechanism for induction of P-eIF $2 \alpha$ and stalling of protein synthesis. In contrast to PERK, there are relatively fewer examples of modulation of PKR activation during microbial infection, predominantly in protozoan infections and with the Gram-negative bacteria Yersinia (Table 4).

Protein kinase $\mathrm{R}$ activation was observed in eukaryotic protozoan parasite infections such as Leishmania amazonensis. This parasite activates both host PKR and PERK pathways, resulting in elevated P-eIF2 $\alpha$ (Pereira et al., 2010; Dias-Teixeira et al., 2017). Interestingly, in response to infection, the first study speculates that the activation of PKR may be due to increased 
expression of PKR activating stimuli other than dsRNA (Pereira et al., 2010), while the later study found that XBP1 splicing also occurred following infection with L. amazonensis suggesting that the UPR pathway was activated along with PKR/PERK/P-eIF2 $\alpha$ activation (Dias-Teixeira et al., 2017).

The protozoan parasite, Toxoplasma gondii, appears to also activate PKR and P-eIF2 $\alpha$ (Portillo et al., 2017). However, this only occurred with the knockdown of the focal adhesion kinase (FAK), suggesting that the organism induces a mechanism to evade the ISR and host autophagy (Portillo et al., 2017).

In contrast to protozoan activation of PKR, the $Y$. pseudotuberculosis virulence factor YopJ was implicated in the inhibition of PKR, HRI, and PERK activation in MEF cells (Shrestha et al., 2012). Paradoxically, while YopJ inhibits the activation of these kinases, this same study found that $Y$. pseudotuberculosis-infected cells have elevated P-eIF2 $\alpha$. YopJ expression in MEFs exhibited an inhibitory effect on three of the four eIF $2 \alpha$ kinases, assessed by reduced ATF4 expression upon PERK, HRI, and PKR activation by kinase-specific-activating drugs in the presence of YopJ. This group had previously found that the $Y$. pseudotuberculosis virulence factor YpkA, increased P-eIF $2 \alpha$ in fission yeast cells (Wiley et al., 2009). YpkA is closely associated with YopJ, and both proteins enter host cells via the T3SS. Taken together, these results are suggestive of YopJ functioning to evade the ISR, while alternative virulence factors, likely YpkA, are inducing elevated P-eIF2 $\alpha$; however, it is unclear as to which eIF2 $\alpha$ kinase is responsible.

\section{General Control Non-derepressible 2 and Heme-Regulated Inhibitor}

The eIF $2 \alpha$ kinases GCN2 and HRI can be activated by multiple stresses. GCN2 is activated by amino acid starvation during infection by a number of organisms that express pore forming toxins, whereas HRI, activated by heme deprivation in erythrocytes, is the least investigated stress kinase in the ISR (Burwick and Aktas, 2017). However, in the few organisms where its activation was observed, it was coupled with the activation of another kinase, suggesting that HRI activation may occur in tandem with other stresses and more commonly activated during infection than previously believed.

Activation of GCN2 has been proposed to be a common host response due to amino acid starvation, first observed in L. monocytogenes along with elevated P-eIF2 $\alpha$ levels (Tattoli et al., 2012). This is in contrast to the proposal of ER stress and PERK activation previously implicated by elevated P-eIF $2 \alpha$ and triggering UPR (ATF6 and IRE1 activation and XBP1 splicing), although PERK activation was not itself examined in this case (Pillich et al., 2012).

Similar mechanisms also appear to occur in pore-forming toxin (PFT)-expressing microbes, which were suggested to activate GCN2 via membrane damage-induced nutrient depletion (Kloft et al., 2010). One such organism, Staphylococcus aureus, expresses the PFT $\alpha$-toxin that was shown to activate GCN2, and interestingly, also PKR; however, the mechanism of activation of this kinase remains unclear (Kloft et al., 2010). They also showed a similar activation of GCN2 in response to other PFTs expressed by microorganisms including Vibrio cholerae (cytolysin), Streptococcus pyogenes (streptolysin), and Escherichia coli (hemolysin A). This would suggest that other organisms producing PFT may share a similar mechanism in promoting GCN2 activation, P-eIF2 $\alpha$, and potentially, SG formation.

Host membrane damage can also cause amino acid starvation resulting in the phosphorylation of GCN2 and eIF2 $\alpha$ in Shigella flexneri and Salmonella typhimurium infection (Tattoli et al., 2012). This was also shown to promote the formation of SGs in both organisms. The same group found that HRI was also activated in S. flexneri infection, and upon knockdown of HRI, the number of cells containing SGs decreased (Abdel-Nour et al., 2019). A similar effect occurred with knockdown of GCN2, while a double knockdown reduced both P-eIF2 $\alpha$ below detection as well as eliminating SGs from cells. Furthermore, these kinases were found to have distinct roles, with HRI alone required for inflammatory responses from the ISR.

Pseudomonas aeruginosa most likely increases the P-eIF $2 \alpha$ in infected cells by multiple kinases (as described above in the PERK section). Other kinases that were implicated in elevated P-eIF $2 \alpha$ during infection include HRI and GCN2. Elevated P-eIF2 $\alpha$ caused downstream protein expression (GADD34 and CHOP) in infected cells, which was tapered by the knockdown of HRI (van 't Wout et al., 2015). A possible mechanism was proposed to be iron depletion. GCN2 and PERK may also be activated by $P$. aeruginosa. One study determined that GCN2 activation occurred dependent on pyocyanin, a $P$. aeruginosa virulence factor (Yang et al., 2016). In addition, as pyocyanin can cause ROS generation (Hall et al., 2016), it is possible that the PERK pathway may also be activated, although this was not examined (Yang et al., 2016).

\section{CAN ANTIBIOTICS ALTER STRESS GRANULE BIOLOGY?}

The dynamics of SGs can be manipulated by drugs and other small molecules, leading to their induction, modification, or disassembly (Wang et al., 2020). Among these, several drugs used for cancer treatment have been shown to impact SGs. One example of such an effect are drugs that cause SG assembly through increased P-eIF2 $\alpha$; these include fluorouracil, etoposide, and cisplatin (García et al., 2011; Kaehler et al., 2014; Vilas-Boas et al., 2016).

Much less is known about the effect of antimicrobial antibiotics on SGs. One example of a clear effect on SGs is the antibiotic puromycin. It is an aminonucleoside antibiotic that has long been used in the study of SGs, due to its ability to promote SG disassembly through premature peptide chain termination and the resulting destabilization of polysomes (Kedersha et al., 2000). Similarly, the antibiotic translation inhibitor anisomycin, which is used as an anti-fungal and anti-protozoan agent, inhibits SG assembly in arsenite-stressed cells (Fang et al., 2019). Interestingly, this study also found that in the absence of external stress, anisomycin increased P-eIF $2 \alpha$ without inducing SG assembly. The effect of anisomycin is not unexpected, as it is 
thought to stall eukaryotic translation similarly to cycloheximide, a common drug used in SG analyses (Chan et al., 2004).

Since antibiotics that target prokaryotic translation do not generally affect eukaryotic translation, they would not be expected to induce SGs by altering translation. However, neomycin, an aminoglycoside prokaryotic protein synthesis inhibitor, reduced the assembly of SGs following an external stress through an unknown mechanism (Fang et al., 2019). This is consistent with the ability of some aminoglycosides to alter eukaryotic translation (Prokhorova et al., 2017). In contrast, another aminoglycoside, kanamycin, was shown to induce SG formation in mouse hair cells (Gonçalves et al., 2019). Its mechanism of action on SG assembly is unclear due to it being 250 -fold less active against eukaryotic translation in vitro than prokaryotic ribosomes (McCoy et al., 2013).

While serendipity can reveal interactions between antibiotics and SG biology, screens have demonstrated that many small molecules impact SGs (Christen et al., 2019; Fang et al., 2019; Wheeler et al., 2019). One of these studies revealed that psammaplysin F, an bactericidal antibiotic produced from a marine sponge, reduced the number of SGs following exposure to sodium arsenite, through decreased P-eIF2 $\alpha$ (Christen et al., 2019). Interestingly, approximately 100 small molecules were identified in another screen of two cell lines where SGs were induced by arsenite, including neomycin, as discussed above (Fang et al., 2019). Unsurprisingly, the majority of the antibiotics affecting SGs in this study were those targeting eukaryotic cells, such as fungi and protozoa, including mebendazole, fenbendazole, and dapsone. One example that stood out in this study was the antibiotic gramicidin S. Gramicidin S targets Grampositive bacteria and fungi and was found to result in fewer SGs and exhibited diffused SG protein fluorescence throughout the cytoplasm. Gramicidin acts to form pores that only allow passage of monovalent cations. The differences and similarities to other bacterial pore-forming toxins would be of interest for further exploration.

Generally speaking, it is clear that some antibiotics can affect SGs. Due to their selectivity for microbes, especially those targeting bacteria, it could be expected that interactions affecting SGs would result from altered mechanisms of action in the host cell. It remains to be investigated to what extent they can exert their effect and the ultimate consequences of their function.

\section{WHAT IS THE IMPACT OF STRESS GRANULES ON MICROBIAL INFECTION?}

Many roles have been ascribed for SGs during viral infection, which have been studied for well over a decade (Eiermann et al., 2020). However, it is clear that infection with many non-viral microbes can also induce SG formation. Potential roles for SGs in the host can be to limit infection and affect intracellular signaling. Recent results suggest two possible manners by which SGs can impact infection. First, the ISR can be activated, elevating P-eIF2 $\alpha$, which inhibits translation and promotes the assembly of SGs. Second, more recent studies suggest an important linkage between innate immunity and SGs.
Studies have not examined the role of SGs per se in inhibition of infection. However, there is clear evidence that P-eIF2 $\alpha$ and the upstream activating kinases can affect infections. What remains unclear is whether these effects are due to the translation inhibition caused by P-eIF $2 \alpha$, or if they are linked to the formation of SGs themselves.

\section{The Integrated Stress Response Can Affect the Outcome of Microbial Infection}

Most studies in this regard have examined activation of the eIF2 $\alpha$ kinase PERK. Drug-induced activation of PERK inhibited microbial infection in several manners. Campylobacter jejuni was shown to be particularly inhibited by PERK activation (Tentaku et al., 2018). Addition of the drugs thapsigargin and tunicamycin reduced the ability for the bacteria to invade Caco-2 cells. Inducing PERK signaling by pre-infection with the bacteria also decreased C. jejuni invasion suggesting an antibacterial role of PERK activation. Finally, knockdown of the three main UPR-signaling proteins (PERK, ATF6, and IRE1) facilitated bacterial infection in HeLa cells. A similar effect was observed in Listeria, where activation of PERK with tunicamycin and thapsigargin decreased recovery of intracellular bacteria (Pillich et al., 2012).

Another mechanism by which ISR could operate to combat infection is by avoidance of host cell apoptosis as exemplified by Mycobacterium bovis (Seimon et al., 2010). Apoptosis of macrophages is thought to be an important host defense against infection. However, infection of murine peritoneal macrophages with this bacteria at low MOI does not cause apoptosis (Seimon et al., 2010). When combined with PERK activation by thapsigargin, there was a significant, up to fivefold synergistic increase in apoptosis. Intriguingly, it has been suggested that virulent Mycobacterium strains have mechanisms to avoid apoptosis and promote survival, of which activation of PERK could be a component (Lam et al., 2017). Thus, inhibition of PERK, P-eIF2 $\alpha$, or SGs could be a generalized mechanism to promote mycobacterial virulence.

In contrast, PERK activation appears beneficial for at least three microbes. First, infection with the intracellular bacteria Brucella melitensis is reduced by inhibition of PERK activation by pre-treatment with tauroursodeoxycholic acid (Smith et al., 2013). This reduced Brucella CFU recovery from RAW cells by at least 10 -fold $24 \mathrm{hpi}$. Second, the protozoan parasite $P$. berghei also appears to benefit from PERK activation by tunicamycin (Inácio et al., 2015). Mice that were intraperitoneally treated with tunicamycin and injected with the parasite had a significant increase in liver infection compared with mice without the drug. Finally, the intracellular bacteria Chlamydia muridarum appears to benefit from UPR activation including PERK activation, both in vitro and in vivo (George et al., 2017). However, this may not implicate SGs, as similar reductions in recovery of inclusionforming units were found in drugs targeting PERK as well as IRE1, which is another arm of the UPR. Nevertheless, these studies together are suggestive that at least for a subset of organisms, depending on the lifestyle, PERK, P-eIF2 $\alpha$, and/or SGs could promote virulence. 
Protein kinase $\mathrm{R}$ was also shown to affect microbial infection. PKR decreased parasite killing through autophagy in Toxoplasma gondii (Ogolla et al., 2013; Portillo et al., 2017). Dominant negative PKR reduced protozoan killing and, in knockout mice, resulted in a greater number of infected mice.

HRI activation is important in combatting Listeria infection (Bahnan et al., 2018). Replication of Listeria increased in macrophages lacking HRI. This was replicated in vivo, where knockout mice were more susceptible to listeriosis. This was further supported by treatment of mice with the P-eIF2 $\alpha$ activator I-17. The elevated P-eIF2 $\alpha$ resulted in a reduced recovery of CFU from peritoneal exudate macrophages.

Finally, expression of the S51A mutant of eIF2 $\alpha$, which cannot be phosphorylated, promotes infection. Chlamydia and Listeria infection results in a greater than fivefold increase in inclusion forming units from knock-in mutant MEF cells, with Yersinia infection exhibiting a 25-fold increase (Shrestha et al., 2012).

\section{STRESS GRANULE RELATIONSHIP WITH THE INNATE IMMUNE RESPONSE}

There are well-established connections between SGs, the innate immune response, and viral infection (Cláudio et al., 2013; Onomoto et al., 2014; McCormick and Khaperskyy, 2017). In contrast, connections between these processes during microbial infection are just beginning to be identified.

In the last few years, new work has shown a convergence between innate immunity pathways and SGs. Two examples are the cytosolic DNA sensor cyclic GMP-AMP synthase (cGAS) and inflammasomes, which activate inflammatory responses including pyroptosis, a lytic form of cell death caused as a result of intracellular infection.

Cyclic GMP-AMP synthase is an important cytoplasmic DNA sensor for detection of microbial or self-DNA. The core SG protein G3BP1 has been shown to associate with cGAS and be critical for its production of type I IFN (Liu et al., 2019). This study suggested that cGAS was not related to SG formation since cGAS was not found in SGs. In addition, knockdown of TIA1, which eliminated SGs, did not affect cGAS signaling. Furthermore, cytoplasmic cGAS foci induced with interferon stimulatory DNA did not colocalize with G3BP1.

However, the extent of SGs' role in cGAS activation remains unclear. A subsequent study supported the finding that G3BP1 regulated cGAS ( $\mathrm{Hu}$ et al., 2019). In contrast to the previous work, the researchers found that the cGAS foci contained G3BP1, PKR, and P-eIF2 $\alpha$. That these foci are SGs is further supported by interferon stimulatory DNA-induced PKR activation and elevated P-eIF2 $\alpha$, dependent on cGAS; however, it remains to be confirmed whether these G3BP1 foci are bona fide SGs.

The NLRP3 inflammasome appears to be more directly affected or regulated by SGs. While SGs promote survival, inflammasomes promote pyroptosis. The DEAD box helicase DDX3X can interact and regulate the NLRP3 inflammasome (Samir et al., 2019). Overexpression of DDX3X has been previously shown to cause SG formation and is impaired when downregulated, although it is likely not involved in SG disassembly (Shih et al., 2011; Cui et al., 2020). The interaction of DDX3X with the inflammasome combines with its role in SG biology as documented in Samir et al. (2019), which demonstrated that SG assembly can prevent the activation of inflammasomes, while pre-assembled inflammasomes are unaffected by SG formation. In contrast to cGAS however, G3BP1 depletion did not affect the function of inflammasomes. This suggests that different immune pathways may be differently affected by SGs and SG proteins.

An interesting connection between innate immunity and SGs is the ability of eIF $2 \alpha$ kinases to regulate the signalosomes, which have been shown to have the ability to form amyloid fibrils (Sohn and Hur, 2016; Girardin et al., 2020). These include the NLRP3 and AIM2 inflammasome, the nodosome, as well as MAVS, TRIF, and RIPK1/RIPK3 amyloid-like fibrils. There is also a connection between innate immunity and amyloid-driven neurodegeneration (Ryu et al., 2018). SGs have numerous links to both neurodegeneration and alternative structures promoted by prion-like proteins (Wolozin and Ivanov, 2019). These connections suggest that infection may result in a variety of effects dependent on SGs and phase separation of signaling proteins.

\section{FUTURE PERSPECTIVES}

In many ways, the current state of SG research in non-viral microbial infection is similar to research into its role during viral infection in the early 2000s (Anderson and Kedersha, 2002). At that time, evidence suggested SG formation as a common response to viral infection, especially as elevated P-eIF $2 \alpha$ levels and eIF $2 \alpha$ kinase activation had been observed during infection. In the nearly two decades since, the extent of the interactions between viruses and SGs have become both clear and extensive (Eiermann et al., 2020). This includes the adaptations in which viruses subvert SGs and their protein components.

Stress granules, and liquid-liquid phase-separated membraneless organelles more generally have been proposed to have multiple roles in the cell. Several of these functions can be important for the host during infection. These include serving as a reaction crucible by concentrating factors within SGs, as an organizational hub (such as seen in the nucleolus and in chromosomes) as well as sequestration of signaling complexes to coordinate responses to stresses including infection (Shin and Brangwynne, 2017).

Currently, these multiple functions remain unexplored. While three bacterial species have been shown to form SGs in infected cells, the studies revealing their existence emphasized the role of the ISR, rather than SGs per se (Tattoli et al., 2012; Vonaesch et al., 2016; Abdel-Nour et al., 2019). SGs were more linked to a consequence of the ISR rather than the active participants in the host cell defense against bacterial infection. However, further study is needed to understand if SGs themselves can affect infection and its outcomes.

Interestingly, the area in microbial infection biology where SGs functions have been examined most explicitly is the 
innate immune response (Hu et al., 2019; Liu et al., 2019; Samir et al., 2019). These results are likely to be extended as SGs become more widely studied as a response to multiple microbial infections.

For example, inflammasomes are important in the innate immune response to bacterial infection (von Moltke et al., 2013). SGs appear to regulate whether they assemble in response to infection mediated by sequestration of the DEAD box helicase DDX3X (Samir et al., 2019). With further study of SGs, this process may be generalizable to many microbial infections. Potential evidence of SGs affecting inflammasomes could be occurring in $S$. pneumoniae. Pneumococcal $\mathrm{H}_{2} \mathrm{O}_{2}$ has been independently shown to inhibit inflammasome assembly and greatly increase P-eIF $2 \alpha$ levels, likely sufficient for SG assembly (Loose et al., 2015; Erttmann and Gekara, 2019).

While SGs have not been examined for specific roles outside of innate immune responses, the upstream activators, as components of the ISR, reveal them as a potentially important element in host defenses against infection. These studies have demonstrated that inhibition of the ISR often positively impacts the infectious organisms in areas such as increased replication. These data also reveal that some intracellular microbes have co-opted this response to promote infection.

In addition, SGs have been shown to be impacted by additional biological processes, which are relevant during microbial infection; however these are beyond the scope of this review. These processes include autophagy, the mTOR signaling pathway, and proteasomal function, among others. First, since autophagy was shown to be important for SG clearing, there has been much work linking the two pathways (Buchan et al., 2013; Abildgaard et al., 2020). Second, mTOR, phosphoinositide 3-kinase (PI3K), and the p38 mitogen-activated protein kinases have been shown to impact SG assembly and infection, making these kinases an interesting avenue for further research (Martin et al., 2012; Fournier et al., 2013; Sfakianos et al., 2018; Heberle et al., 2019). Finally, a linkage has been found between the ubiquitin-proteasome system and both SG assembly

\section{REFERENCES}

Abdel-Nour, M., Carneiro, L. A. M., Downey, J., Tsalikis, J., Outlioua, A., Prescott, D., et al. (2019). The heme-regulated inhibitor is a cytosolic sensor of protein misfolding that controls innate immune signaling. Science 365:eaaw4144. doi: 10.1126/science.aaw4144

Abildgaard, M. H., Brynjólfsdóttir, S. H., and Frankel, L. B. (2020). The autophagyRNA interplay: degradation and beyond. Trends Biochem. Sci. 45, 845-857. doi: 10.1016/j.tibs.2020.07.007

Adomavicius, T., Guaita, M., Zhou, Y., Jennings, M. D., Latif, Z., Roseman, A. M., et al. (2019). The structural basis of translational control by eIF2 phosphorylation. Nat. Commun. 10:2136. doi: 10.1038/s41467-01910167-3

Anand, S. S., and Babu, P. P. (2013). Endoplasmic reticulum stress and neurodegeneration in experimental cerebral malaria. Neurosignals 21, 99-111. doi: 10.1159/000336970

Anderson, P., and Kedersha, N. (2002). Stressful initiations. J. Cell Sci. 115:3227.

Bahnan, W., Boucher, J. C., Gayle, P., Shrestha, N., Rosen, M., Aktas, B., et al. (2018). The eIF2 $\alpha$ Kinase Heme-regulated inhibitor protects the host and microbial infection (Mazroui et al., 2007; Lin and Machner, 2017).

In this review, we have outlined studies in which SGs have been identified during non-viral microbial infection. We argue that host SG assembly is a widespread reaction to microbial infection. The ISR, that is elevated P-eIF2 $\alpha$ and eIF $2 \alpha$ kinase activation, appears to be a general response to microbial infections. As a result of ISR activation, these infections can form SGs. Further investigation into the role of SGs during infection should reveal important antimicrobial functions imparted by SGs. Analogous to viral infections, these studies also reveal exceptions to ISR activation and suggest that microbes may also have the ability to not only inhibit SG formation but also assist in their disassembly. This suggests that microbial infections, like viral infections, may provoke adaptations to modulate the SG response.

\section{AUTHOR CONTRIBUTIONS}

AT and TN wrote the manuscript, made substantial, direct and intellectual contribution to the work, and approved it for publication. Both authors contributed to the article and approved the submitted version.

\section{FUNDING}

This research was supported by a grant from Vetenskapsrådet (The Swedish Research Council) 2017-04663 to TN.

\section{ACKNOWLEDGMENTS}

We apologize to those authors whose work we could not cite owing to space limitations. The figures were created with BioRender.com. Dedicated to the memory of Professor Marie Öhman, RNA biologist at Stockholm University.

from infection by regulating intracellular pathogen trafficking. Infect. Immun 86:e0707-17. doi: 10.1128/IAI.00707-17

Besic, V., Habibolahi, F., Noël, B., Rupp, S., Genovesio, A., and Lebreton, A. (2020). Coordination of transcriptional and translational regulations in human epithelial cells infected by Listeria monocytogenes. RNA Biol. 17, 1492-1507. doi: 10.1080/15476286.2020.1777380

Böhme, L., Albrecht, M., Riede, O., and Rudel, T. (2010). Chlamydia trachomatisinfected host cells resist dsRNA-induced apoptosis. Cell. Microbiol. 12, 1340 1351. doi: 10.1111/j.1462-5822.2010.01473.x

Bounedjah, O., Hamon, L., Savarin, P., Desforges, B., Curmi, P. A., and Pastré, D. (2012). Macromolecular crowding regulates assembly of mRNA stress granules after osmotic stress: new role for compatible osmolytes. J. Biol. Chem. 287, 2446-2458. doi: 10.1074/jbc.M111.292748

Brostrom, C. O., and Brostrom, M. A. (1997). "Regulation of translational initiation during cellular responses to stress," in Progress in Nucleic Acid Research and Molecular Biology, ed. K. Moldave (Cambridge, MA: Academic Press), 79-125. doi: 10.1016/S0079-6603(08)60034-3

Buchan, J. R., Kolaitis, R.-M., Taylor, J. P., and Parker, R. (2013). Eukaryotic stress granules are cleared by autophagy and Cdc48/VCP Function. Cell 153, 1461-1474. doi: 10.1016/j.cell.2013.05.037 
Burwick, N., and Aktas, B. H. (2017). The eIF2-alpha kinase HRI: a potential target beyond the red blood cell. Expert Opin. Ther. Targets 21, 1171-1177. doi: 10.1080/14728222.2017.1397133

Celli, J., and Tsolis, R. M. (2015). Bacteria, the endoplasmic reticulum and the unfolded protein response: friends or foes? Nat. Rev. Microbiol. 13, 71-82. doi: $10.1038 /$ nrmicro3393

Chan, J., Khan, S. N., Harvey, I., Merrick, W., and Pelletier, J. (2004). Eukaryotic protein synthesis inhibitors identified by comparison of cytotoxicity profiles. RNA 10, 528-543. doi: 10.1261/rna.5200204

Choi, H.-H., Shin, D.-M., Kang, G., Kim, K.-H., Park, J. B., Hur, G. M., et al. (2010). Endoplasmic reticulum stress response is involved in Mycobacterium tuberculosis protein ESAT-6-mediated apoptosis. FEBS Lett. 584, 2445-2454. doi: 10.1016/j.febslet.2010.04.050

Choi, J.-A., Lim, Y.-J., Cho, S.-N., Lee, J.-H., Jeong, J. A., Kim, E. J., et al. (2013). Mycobacterial HBHA induces endoplasmic reticulum stress-mediated apoptosis through the generation of reactive oxygen species and cytosolic Ca2+ in murine macrophage RAW 264.7 cells. Cell Death Dis. 4:e957. doi: 10.1038/ cddis.2013.489

Christen, K. E., Davis, R. A., and Kennedy, D. (2019). Psammaplysin F increases the efficacy of bortezomib and sorafenib through regulation of stress granule formation. Int. J. Biochem. Cell Biol. 112, 24-38. doi: 10.1016/j.biocel.2019.04. 008

Cláudio, N., Dalet, A., Gatti, E., and Pierre, P. (2013). Mapping the crossroads of immune activation and cellular stress response pathways. EMBO J. 32, 1214-1224. doi: 10.1038/emboj.2013.80

Coburn, B., Sekirov, I., and Finlay, B. B. (2007). Type III secretion systems and disease. Clin. Microbiol. Rev. 20:535. doi: 10.1128/CMR.00013-07

Cui, B. C., Sikirzhytski, V., Aksenova, M., Lucius, M. D., Levon, G. H., Mack, Z. T., et al. (2020). Pharmacological inhibition of DEAD-Box RNA Helicase 3 attenuates stress granule assembly. Biochem. Pharmacol. 182:114280. doi: 10.1016/j.bcp.2020.114280

de Jong, M. F., Starr, T., Winter, M. G., den Hartigh, A. B., Child, R., Knodler, L. A., et al. (2013). Sensing of bacterial Type IV secretion via the unfolded protein response. mBio 4:e0418-12. doi: 10.1128/mBio.00418-12

Dias-Teixeira, K. L., Calegari-Silva, T. C., Medina, J. M., Vivarini, ÁC., Cavalcanti, Á, Teteo, N., et al. (2017). Emerging role for the PERK/eIF2 $\alpha /$ ATF4 in Human Cutaneous Leishmaniasis. Sci. Rep. 7:17074. doi: 10.1038/s41598-017-17252-x

Eiermann, N., Haneke, K., Sun, Z., Stoecklin, G., and Ruggieri, A. (2020). Dance with the devil: stress granules and signaling in antiviral responses. Viruses 12:984. doi: 10.3390/v12090984

English, B. C., Van Prooyen, N., Örd, T., Örd, T., and Sil, A. (2017). The transcription factor CHOP, an effector of the integrated stress response, is required for host sensitivity to the fungal intracellular pathogen Histoplasma capsulatum. PLoS Pathog. 13:e1006589. doi: 10.1371/journal.ppat.1006589

Erttmann, S. F., and Gekara, N. O. (2019). Hydrogen peroxide release by bacteria suppresses inflammasome-dependent innate immunity. Nat. Commun. 10:3493. doi: 10.1038/s41467-019-11169-x

Fang, M. Y., Markmiller, S., Vu, A. Q., Javaherian, A., Dowdle, W. E., Jolivet, P., et al. (2019). Small-molecule modulation of TDP-43 recruitment to stress granules prevents persistent TDP-43 accumulation in ALS/FTD. Neuron 103, 802-819.e11. doi: 10.1016/j.neuron.2019.05.048

Fournier, M.-J., Coudert, L., Mellaoui, S., Adjibade, P., Gareau, C., Côté, M.F., et al. (2013). Inactivation of the mTORC1-eukaryotic translation initiation factor 4E pathway alters stress granule formation. Mol. Cell. Biol. 33:2285. doi: 10.1128/MCB.01517-12

Frädrich, C., Beer, L.-A., and Gerhard, R. (2016). Reactive oxygen species as additional determinants for Cytotoxicity of Clostridium difficile Toxins A and B. Toxins 8:25.

García, M. A., Carrasco, E., Aguilera, M., Alvarez, P., Rivas, C., Campos, J. M., et al. (2011). The chemotherapeutic Drug 5-fluorouracil promotes PKR-mediated apoptosis in a p53- independent manner in colon and breast cancer cells. PLoS One 6:e23887. doi: 10.1371/journal.pone.0023887

García, M. A., Gil, J., Ventoso, I., Guerra, S., Domingo, E., Rivas, C., et al. (2006). Impact of protein kinase PKR in cell biology: from antiviral to antiproliferative action. Microbiol. Mol. Biol. Rev. 70, 1032-1060. doi: 10.1128/MMBR.00027-06

Gekara, N. O., Groebe, L., Viegas, N., and Weiss, S. (2008). Listeria monocytogenes desensitizes immune cells to subsequent $\mathrm{Ca} 2+$ signaling via Listeriolysin
O-induced depletion of intracellular Ca2+ stores. Infect. Immun. 76:857. doi: 10.1128/IAI.00622-07

George, Z., Omosun, Y., Azenabor, A. A., Goldstein, J., Partin, J., Joseph, K., et al. (2019). The molecular mechanism of induction of unfolded protein response by Chlamydia. Biochem. Biophys. Res. Commun. 508, 421-429. doi: 10.1016/j.bbrc. 2018.11.034

George, Z., Omosun, Y., Azenabor, A. A., Partin, J., Joseph, K., Ellerson, D., et al. (2017). The Roles of unfolded protein response pathways in chlamydia pathogenesis. J. Infect. Dis. 215, 456-465. doi: 10.1093/infdis/jiw569

Girardin, S. E., Cuziol, C., Philpott, D. J., and Arnoult, D. (2020). The eIF2 $\alpha$ kinase HRI in innate immunity, proteostasis, and mitochondrial stress. FEBS J. doi: 10.1111/febs.15553. [Epub ahead of print].

Go, D., Lee, J., Choi, J.-A., Cho, S.-N., Kim, S.-H., Son, S.-H., et al. (2019). Reactive oxygen species-mediated endoplasmic reticulum stress response induces apoptosis of Mycobacterium avium-infected macrophages by activating regulated IRE1-dependent decay pathway. Cell. Microbiol. 21:e13094. doi: 10. $1111 / \mathrm{cmi} .13094$

Gonçalves, A. C., Towers, E. R., Haq, N., Porco, J. A., Pelletier, J., Dawson, S. J., et al. (2019). Drug-induced stress granule formation protects sensory hair cells in mouse cochlear explants during Ototoxicity. Sci. Rep. 9:12501. doi: 10.1038/ s41598-019-48393-w

Gonzalez, M. R., Bischofberger, M., Frêche, B., Ho, S., Parton, R. G., and van der Goot, F. G. (2011). Pore-forming toxins induce multiple cellular responses promoting survival. Cell. Microbiol. 13, 1026-1043. doi: 10.1111/j.1462-5822. 2011.01600.x

Grabiner, M. A., Fu, Z., Wu, T., Barry, K. C., Schwarzer, C., and Machen, T. E. (2014). Pseudomonas aeruginosa quorum-sensing molecule homoserine lactone modulates inflammatory signaling through PERK and eI-F2 $\alpha$. J. Immunol. 193:1459. doi: 10.4049/jimmunol.1303437

Grohmann, E., Christie, P. J., Waksman, G., and Backert, S. (2018). Type IV secretion in Gram-negative and Gram-positive bacteria. Mol. Microbiol. 107, 455-471. doi: 10.1111/mmi.13896

Grönberg, A., Zettergren, L., Bergh, K., Ståhle, M., Heilborn, J., Ängeby, K., et al. (2010). Antioxidants protect Keratinocytes against M. ulcerans mycolactone Cytotoxicity. PLoS One 5:e13839. doi: 10.1371/journal.pone.0013839

Guillén-Boixet, J., Kopach, A., Holehouse, A. S., Wittmann, S., Jahnel, M., Schlüßler, R., et al. (2020). RNA-induced conformational switching and clustering of G3BP drive stress granule assembly by condensation. Cell 181, 346-361.e17. doi: 10.1016/j.cell.2020.03.049

Hall, S., McDermott, C., Anoopkumar-Dukie, S., McFarland, A., Forbes, A., Perkins, A. V., et al. (2016). Cellular effects of Pyocyanin, a secreted virulence factor of Pseudomonas aeruginosa. Toxins 8:236.

Hanada, H., Ikeda-Dantsuji, Y., Naito, M., and Nagayama, A. (2003). Infection of human fibroblast-like synovial cells with Chlamydia trachomatis results in persistent infection and interleukin-6 production. Microb. Pathog. 34, 57-63. doi: 10.1016/S0882-4010(02)00189-4

Hanson, K. K., and Mair, G. R. (2014). Stress granules and Plasmodium liver stage infection. Biol. Open 3:103. doi: 10.1242/bio.20136833

Heberle, A. M., Razquin Navas, P., Langelaar-Makkinje, M., Kasack, K., Sadik, A., Faessler, E., et al. (2019). The PI3K and MAPK/p38 pathways control stress granule assembly in a hierarchical manner. Life Sci. Alliance 2:e201800257. doi: $10.26508 /$ lsa.201800257

Hershey, J. W. B. (1989). Protein phosphorylation controls translation rates. J. Biol. Chem. 264, 20823-20826.

Hofmann, S., Kedersha, N., Anderson, P., and Ivanov, P. (2021). Molecular mechanisms of stress granule assembly and disassembly. Biochim. Biophys. Acta Mol. Cell Res. 1868:118876. doi: 10.1016/j.bbamcr.2020.118876

$\mathrm{Hu}, \mathrm{L}$. , Raybourne, R. B., and Kopecko, D. J. (2005). Ca2+ release from host intracellular stores and related signal transduction during Campylobacter jejuni 81-176 internalization into human intestinal cells. Microbiology 151, 30973105 .

Hu, S., Sun, H., Yin, L., Li, J., Mei, S., Xu, F., et al. (2019). PKR-dependent cytosolic cGAS foci are necessary for intracellular DNA sensing. Sci. Signal. 12:eaav7934. doi: 10.1126/scisignal.aav7934

Ietta, F., Maioli, E., Daveri, E., Gonzaga Oliveira, J., da Silva, R. J., Romagnoli, R., et al. (2017). Rottlerin-mediated inhibition of Toxoplasma gondii growth in BeWo trophoblast-like cells. Sci. Rep. 7:1279. doi: 10.1038/s41598-017-01525-6 
Inácio, P., Zuzarte-Luís, V., Ruivo, M. T., Falkard, B., Nagaraj, N., Rooijers, K., et al. (2015). Parasite-induced ER stress response in hepatocytes facilitates Plasmodium liver stage infection. EMBO Rep. 16, 955-964. doi: 10.15252/embr. 201439979

Jalihal, A. P., Pitchiaya, S., Xiao, L., Bawa, P., Jiang, X., Bedi, K., et al. (2020). Multivalent proteins rapidly and reversibly phase-separate upon osmotic cell volume change. Mol. Cell 79, 978-990.e5. doi: 10.1016/j.molcel.2020.08.004

Kaehler, C., Isensee, J., Hucho, T., Lehrach, H., and Krobitsch, S. (2014). 5Fluorouracil affects assembly of stress granules based on RNA incorporation. Nucleic Acids Res. 42, 6436-6447. doi: 10.1093/nar/gku264

Kedersha, N., Cho, M. R., Li, W., Yacono, P. W., Chen, S., Gilks, N., et al. (2000). Dynamic shuttling of Tia-1 accompanies the recruitment of mRNA to mammalian stress granules. J. Cell Biol. 151, 1257-1268. doi: 10.1083/jcb.151.6. 1257

Kiehn, T. E., Edwards, F. F., Brannon, P., Tsang, A. Y., Maio, M., Gold, J. W., et al. (1985). Infections caused by Mycobacterium avium complex in immunocompromised patients: diagnosis by blood culture and fecal examination, antimicrobial susceptibility tests, and morphological and seroagglutination characteristics. J. Clin. Microbiol. 21:168.

Kloft, N., Neukirch, C., Bobkiewicz, W., Veerachato, G., Busch, T., von Hoven, G., et al. (2010). Pro-autophagic signal induction by bacterial pore-forming toxins. Med. Microbiol. Immunol. 199, 299-309. doi: 10.1007/s00430-010-0163-0

Kopp, M. C., Larburu, N., Durairaj, V., Adams, C. J., and Ali, M. M. U. (2019). UPR proteins IRE1 and PERK switch BiP from chaperone to ER stress sensor. Nat. Struct. Mol. Biol. 26, 1053-1062. doi: 10.1038/s41594-019-0324-9

Lam, A., Prabhu, R., Gross, C. M., Riesenberg, L. A., Singh, V., and Aggarwal, S. (2017). Role of apoptosis and autophagy in tuberculosis. Am. J. Physiol. Lung Cell Mol. Physiol. 313, L218-L229. doi: 10.1152/ajplung.00162.2017

Lee, S.-Y., Lee, M.-S., Cherla, R. P., and Tesh, V. L. (2008). Shiga toxin 1 induces apoptosis through the endoplasmic reticulum stress response in human monocytic cells. Cell. Microbiol. 10, 770-780. doi: 10.1111/j.1462-5822.2007. 01083.x

Lim, Y.-J., Choi, J.-A., Choi, H.-H., Cho, S.-N., Kim, H.-J., Jo, E.-K., et al. (2011). Endoplasmic reticulum stress pathway-mediated apoptosis in macrophages contributes to the survival of Mycobacterium tuberculosis. PLoS One 6:e28531. doi: 10.1371/journal.pone.0028531

Lim, Y.-J., Choi, J.-A., Lee, J.-H., Choi, C. H., Kim, H.-J., and Song, C.-H. (2015). Mycobacterium tuberculosis $38-\mathrm{kDa}$ antigen induces endoplasmic reticulum stress-mediated apoptosis via toll-like receptor 2/4. Apoptosis 20, 358-370. doi: 10.1007/s10495-014-1080-2

Lin, Y.-H., and Machner, M. P. (2017). Exploitation of the host cell ubiquitin machinery by microbial effector proteins. J. Cell Sci. 130:1985. doi: 10.1242/jcs. 188482

Liu, Z.-S., Cai, H., Xue, W., Wang, M., Xia, T., Li, W.-J., et al. (2019). G3BP1 promotes DNA binding and activation of cGAS. Nat. Immunol. 20, 18-28. doi: 10.1038/s41590-018-0262-4

Lloyd, R. E. (2012). How do viruses interact with stress-associated RNA granules? PLoS Pathog. 8:e1002741. doi: 10.1371/journal.ppat.1002741

Loose, M., Hudel, M., Zimmer, K.-P., Garcia, E., Hammerschmidt, S., Lucas, R., et al. (2015). Pneumococcal hydrogen peroxide-induced stress signaling regulates inflammatory genes. J. Infect. Dis. 211, 306-316. doi: 10.1093/infdis/ jiu428

Martin, S., Saha, B., and Riley, J. L. (2012). The battle over mTOR: an emerging theatre in host-pathogen immunity. PLoS Pathog. 8:e1002894. doi: 10.1371/ journal.ppat.1002894

Masson, G. R. (2019). Towards a model of GCN2 activation. Biochem. Soc. Trans. 47, 1481-1488. doi: 10.1042/BST20190331

Mazroui, R., Di Marco, S., Kaufman, R. J., and Gallouzi, I.-E. (2007). Inhibition of the ubiquitin-proteasome system induces stress granule formation. Mol. Biol. Cell 18, 2603-2618. doi: 10.1091/mbc.e06-12-1079

McCormick, C., and Khaperskyy, D. A. (2017). Translation inhibition and stress granules in the antiviral immune response. Nat. Rev. Immunol. 17, 647-660. doi: $10.1038 /$ nri.2017.63

McCoy, L. S., Roberts, K. D., Nation, R. L., Thompson, P. E., Velkov, T., Li, J., et al. (2013). Polymyxins and analogues bind to ribosomal RNA and interfere with eukaryotic translation in vitro. Chembiochem 14, 2083-2086. doi: 10.1002/cbic. 201300496
Mehlitz, A., Karunakaran, K., Herweg, J.-A., Krohne, G., van de Linde, S., Rieck, E., et al. (2014). The chlamydial organism Simkania negevensis forms ER vacuole contact sites and inhibits ER-stress. Cell. Microbiol. 16, 1224-1243. doi: 10.1111/ cmi.12278

Morinaga, N., Yahiro, K., Matsuura, G., Moss, J., and Noda, M. (2008). Subtilase cytotoxin, produced by Shiga-toxigenic Escherichia coli, transiently inhibits protein synthesis of Vero cells via degradation of $\mathrm{BiP}$ and induces cell cycle arrest at G1 by downregulation of cyclin D1. Cell. Microbiol. 10, 921-929. doi: 10.1111/j.1462-5822.2007.01094.x

Moulder, J. W. (1991). Interaction of chlamydiae and host cells in vitro. Microbiol. Rev. 55:143.

Mpiga, P., and Ravaoarinoro, M. (2006). Chlamydia trachomatis persistence: an update. Microbiol. Res. 161, 9-19. doi: 10.1016/j.micres.2005.04.004

Ogbechi, J., Hall, B. S., Sbarrato, T., Taunton, J., Willis, A. E., Wek, R. C., et al. (2018). Inhibition of Sec61-dependent translocation by mycolactone uncouples the integrated stress response from ER stress, driving cytotoxicity via translational activation of ATF4. Cell Death Dis. 9:397. doi: 10.1038/s41419018-0427-y

Ogolla, P. S., Portillo, J.-A. C., White, C. L., Patel, K., Lamb, B., Sen, G. C., et al. (2013). The Protein Kinase double-stranded RNA-dependent (PKR) enhances protection against disease cause by a non-viral pathogen. PLoS Pathog. 9:e1003557. doi: 10.1371/journal.ppat.1003557

Ohmer, M., Tzivelekidis, T., Niedenführ, N., Volceanov-Hahn, L., Barth, S., Vier, J., et al. (2019). Infection of HeLa cells with Chlamydia trachomatis inhibits protein synthesis and causes multiple changes to host cell pathways. Cell. Microbiol. 21:e12993. doi: 10.1111/cmi.12993

Onomoto, K., Yoneyama, M., Fung, G., Kato, H., and Fujita, T. (2014). Antiviral innate immunity and stress granule responses. Trends Immunol. 35, 420-428. doi: 10.1016/j.it.2014.07.006

Pakos-Zebrucka, K., Koryga, I., Mnich, K., Ljujic, M., Samali, A., and Gorman, A. M. (2016). The integrated stress response. EMBO Rep. 17, 1374-1395. doi: 10.15252/embr.201642195

Pan, Q., Wang, X., Liu, T., Yu, Y., Li, L., Zhou, R., et al. (2020). Mycoplasma hyopneumoniae inhibits Porcine Beta-Defensin 2 production by blocking the unfolded protein response to facilitate epithelial adhesion and infection. Infect. Immun. 88:e0164-20. doi: 10.1128/IAI.00164-20

Pereira, R. M. S., Dias Teixeira, K. L., Barreto-de-Souza, V., Calegari-Silva, T. C., De-Melo, L. D. B., Soares, D. C., et al. (2010). Novel role for the double-stranded RNA-activated protein kinase PKR: modulation of macrophage infection by the protozoan parasite Leishmania. FASEB J. 24, 617-626. doi: 10.1096/fj.09140053

Pillich, H., Loose, M., Zimmer, K.-P., and Chakraborty, T. (2012). Activation of the unfolded protein response by Listeria monocytogenes. Cell. Microbiol. 14, 949-964. doi: 10.1111/j.1462-5822.2012.01769.x

Portillo, J.-A. C., Muniz-Feliciano, L., Lopez Corcino, Y., Lee, S. J., Van Grol, J., Parsons, S. J., et al. (2017). Toxoplasma gondii induces FAK-Src-STAT3 signaling during infection of host cells that prevents parasite targeting by autophagy. PLoS Pathog. 13:e1006671. doi: 10.1371/journal.ppat.1006671

Prokhorova, I., Altman, R. B., Djumagulov, M., Shrestha, J. P., Urzhumtsev, A., Ferguson, A., et al. (2017). Aminoglycoside interactions and impacts on the eukaryotic ribosome. Proc. Natl. Acad. Sci. U.S.A. 114:E10899. doi: 10.1073/ pnas.1715501114

Repp, H., Pamukçi, Z., Koschinski, A., Domann, E., Darji, A., Birringer, J., et al. (2002). Listeriolysin of Listeria monocytogenes forms Ca2+-permeable pores leading to intracellular Ca2+ oscillations. Cell. Microbiol. 4, 483-491. doi: 10. 1046/j.1462-5822.2002.00207.x

Riggs, C. L., Kedersha, N., Ivanov, P., and Anderson, P. (2020). Mammalian stress granules and P bodies at a glance. J. Cell Sci. 133:jcs242487. doi: 10.1242/jcs. 242487

Ruggieri, A., Dazert, E., Metz, P., Hofmann, S., Bergeest, J.-P., Mazur, J., et al. (2012). Dynamic oscillation of translation and stress granule formation mark the cellular response to virus infection. Cell Host Microb. 12, 71-85. doi: 10. 1016/j.chom.2012.05.013

Ryu, J. K., Rafalski, V. A., Meyer-Franke, A., Adams, R. A., Poda, S. B., Rios Coronado, P. E., et al. (2018). Fibrin-targeting immunotherapy protects against neuroinflammation and neurodegeneration. Nat. Immunol. 19, 1212-1223. doi: 10.1038/s41590-018-0232-x 
Sadighi Akha, A. A., Theriot, C. M., Erb-Downward, J. R., McDermott, A. J., Falkowski, N. R., Tyra, H. M., et al. (2013). Acute infection of mice with Clostridium difficile leads to eIF2 $\alpha$ phosphorylation and pro-survival signalling as part of the mucosal inflammatory response. Immunology 140, 111-122. doi: 10.1111/imm.12122

Samir, P., Kesavardhana, S., Patmore, D. M., Gingras, S., Malireddi, R. K. S., Karki, R., et al. (2019). DDX3X acts as a live-or-die checkpoint in stressed cells by regulating NLRP3 inflammasome. Nature 573, 590-594. doi: 10.1038/s41586019-1551-2

Sanders, D. W., Kedersha, N., Lee, D. S. W., Strom, A. R., Drake, V., Riback, J. A., et al. (2020). Competing Protein-RNA interaction networks control multiphase intracellular organization. Cell 181, 306-324.e28. doi: 10.1016/j.cell.2020.03. 050

Schröder, M. (2008). Endoplasmic reticulum stress responses. Cell. Mole. Life Sci. 65, 862-894. doi: 10.1007/s00018-007-7383-5

Seimon, T. A., Kim, M.-J., Blumenthal, A., Koo, J., Ehrt, S., Wainwright, H., et al. (2010). Induction of ER stress in macrophages of Tuberculosis granulomas. PLoS One 5:e12772. doi: 10.1371/journal.pone.0012772

Sfakianos, A. P., Mellor, L. E., Pang, Y. F., Kritsiligkou, P., Needs, H., AbouHamdan, H., et al. (2018). The mTOR-S6 kinase pathway promotes stress granule assembly. Cell Death Differ. 25, 1766-1780. doi: 10.1038/s41418-0180076-9

Shih, J.-W., Wang, W.-T., Tsai, T.-Y., Kuo, C.-Y., Li, H.-K., and Wu Lee, Y.H. (2011). Critical roles of RNA helicase DDX3 and its interactions with eIF4E/PABP1 in stress granule assembly and stress response. Biochem. J. 441, 119-129. doi: 10.1042/BJ20110739

Shima, K., Klinger, M., Schütze, S., Kaufhold, I., Solbach, W., Reiling, N., et al. (2015). The role of endoplasmic reticulum-related BiP/GRP78 in interferon gamma-induced persistent Chlamydia pneumoniae infection. Cell. Microbiol. 17, 923-934. doi: $10.1111 / \mathrm{cmi} .12416$

Shin, Y., and Brangwynne, C. P. (2017). Liquid phase condensation in cell physiology and disease. Science 357:eaaf4382. doi: 10.1126/science.aaf4382

Shrestha, N., Bahnan, W., Wiley, D. J., Barber, G., Fields, K. A., and Schesser, K. (2012). Eukaryotic Initiation Factor 2 (eIF2) signaling regulates proinflammatory cytokine expression and bacterial invasion. J. Biol. Chem. 287, 28738-28744. doi: 10.1074/jbc.M112.375915

Smith, J. A., Khan, M., Magnani, D. D., Harms, J. S., Durward, M., Radhakrishnan, G. K., et al. (2013). Brucella induces an unfolded protein response via TcpB that supports intracellular replication in macrophages. PLoS Pathog. 9:e1003785. doi: 10.1371 /journal.ppat.1003785

Sohn, J., and Hur, S. (2016). Filament assemblies in foreign nucleic acid sensors. Curr. Opin. Struc. Biol. 37, 134-144. doi: 10.1016/j.sbi.2016.01.011

Song, E. J., Lee, S.-J., Lim, H. S., Kim, J. S., Jang, K. K., Choi, S. H., et al. (2016). Vibrio vulnificus VvhA induces autophagy-related cell death through the lipid raft-dependent c-Src/NOX signaling pathway. Sci. Rep. 6:27080. doi: 10.1038/ srep27080

Sun, C., Wang, H., Chen, S., Li, Z., Li, S., and Wang, J. (2014). Recombinant Clostridium difficile toxin B induces endoplasmic reticulum stress in mouse colonal carcinoma cells. Acta Biochim. Biophys. Sin. 46, 973-981. doi: 10.1093/ abbs/gmu091

Tattoli, I., Sorbara, M. T., Vuckovic, D., Ling, A., Soares, F., Carneiro, L. A. M., et al. (2012). Amino acid starvation induced by invasive bacterial pathogens triggers an innate host defense program. Cell Host Microb. 11, 563-575. doi: 10.1016/j.chom.2012.04.012

Tattoli, I., Sorbara, M. T., Yang, C., Tooze, S. A., Philpott, D. J., and Girardin, S. E. (2013). Listeria phospholipases subvert host autophagic defenses by stalling preautophagosomal structures. EMBO J. 32, 3066-3078. doi: 10.1038/emboj.2013. 234

Tentaku, A., Shimohata, T., Hatayama, S., Kido, J., Nguyen, A. Q., Kanda, Y., et al. (2018). Host cellular unfolded protein response signaling regulates Campylobacter jejuni invasion. PLoS One 13:e205865. doi: 10.1371/journal. pone. 0205865

van 't Wout, E. F. A., van Schadewijk, A., van Boxtel, R., Dalton, L. E., Clarke, H. J., Tommassen, J., et al. (2015). Virulence factors of Pseudomonas aeruginosa induce both the unfolded protein and integrated stress responses in airway epithelial cells88. PLoS Pathog. 11:e1004946. doi: 10.1371/journal.ppat.1004946
Vilas-Boas, F. A. D. S., da Silva, A. M., de Sousa, L. P., Lima, K. M., Vago, J. P., Bittencourt, L. F. F. et al. (2016). Impairment of stress granule assembly via inhibition of the eIF2alpha phosphorylation sensitizes glioma cells to chemotherapeutic agents. J. Neurooncol. 127, 253-260. doi: 10.1007/s11060015-2043-3

von Hoven, G., Kloft, N., Neukirch, C., Ebinger, S., Bobkiewicz, W., Weis, S., et al. (2012). Modulation of translation and induction of autophagy by bacterial exoproducts. Med. Microbiol. Immunol. 201, 409-418. doi: 10.1007/s00430012-0271-0

von Moltke, J., Ayres, J. S., Kofoed, E. M., Chavarría-Smith, J., and Vance, R. E. (2013). Recognition of bacteria by inflammasomes. Annu. Rev. Immunol. 31, 73-106. doi: 10.1146/annurev-immunol-032712-095944

Vonaesch, P., Campbell-Valois, F.-X., Dufour, A., Sansonetti, P. J., and Schnupf, P. (2016). Shigella flexneri modulates stress granule composition and inhibits stress granule aggregation. Cell. Microbiol. 18, 982-997. doi: 10.1111/cmi.12561

Walter, P., and Ron, D. (2011). The unfolded protein response: from stress pathway to homeostatic regulation. Science 334:1081. doi: 10.1126/science. 1209038

Wang, F., Li, J., Fan, S., Jin, Z., and Huang, C. (2020). Targeting stress granules: a novel therapeutic strategy for human diseases. Pharmacol. Res. 161:105143. doi: 10.1016/j.phrs.2020.105143

Webster, S. J., Ellis, L., O’Brien, L. M., Tyrrell, B., Fitzmaurice, T. J., Elder, M. J., et al. (2016). IRE $1 \alpha$ mediates PKR activation in response to Chlamydia trachomatis infection. Microb. Infect. 18, 472-483. doi: 10.1016/j.micinf.2016.03.010

Wek, R. C. (2018). Role of eIF2 $\alpha$ kinases in translational control and adaptation to cellular stress. Cold Spring Harb. Perspect. Biol. 10:a032870. doi: 10.1101/ cshperspect.a032870

Wen, Y., Luo, F., Zhao, Y., Su, S., Shu, M., and Li, Z. (2020). Chlamydia trachomatis plasmid-encoded protein pORF5 activates unfolded protein response to induce autophagy via MAPK/ERK signaling pathway. Biochem. Biophys. Res. Commun. 527, 805-810. doi: 10.1016/j.bbrc.2020.04.117

Wheeler, R. J., Lee, H. O., Poser, I., Pal, A., Doeleman, T., Kishigami, S., et al. (2019). Small molecules for modulating protein driven liquid-liquid phase separation in treating neurodegenerative disease. bioRxiv [Preprint]. doi: 10.1101/721001

White, J. P., and Lloyd, R. E. (2012). Regulation of stress granules in virus systems. Trends Microbiol. 20, 175-183. doi: 10.1016/j.tim.2012.02.001

Wiley, D. J., Shrestha, N., Yang, J., Atis, N., Dayton, K., and Schesser, K. (2009). The activities of the Yersinia protein kinase A (YpkA) and outer protein $\mathrm{J}$ (YopJ) virulence factors converge on an eIF2alpha kinase. J. Biol. Chem. 284, 24744-24753. doi: 10.1074/jbc.M109.010140

Wolfson, J. J., May, K. L., Thorpe, C. M., Jandhyala, D. M., Paton, J. C., and Paton, A. W. (2008). Subtilase cytotoxin activates PERK, IRE1 and ATF6 endoplasmic reticulum stress-signalling pathways. Cell. Microbiol. 10, 1775-1786. doi: 10. $1111 /$ j.1462-5822.2008.01164.x

Wolozin, B., and Ivanov, P. (2019). Stress granules and neurodegeneration. Nat. Rev. Neurosci. 20, 649-666. doi: 10.1038/s41583-019-0222-5

Yang, P., Mathieu, C., Kolaitis, R.-M., Zhang, P., Messing, J., Yurtsever, U., et al. (2020). G3BP1 is a tunable switch that triggers phase separation to assemble stress granules. Cell 181, 325-345.e28. doi: 10.1016/j.cell.2020.03.046

Yang, Z.-S., Ma, L.-Q., Zhu, K., Yan, J.-Y., Bian, L., Zhang, K.-Q., et al. (2016). Pseudomonas toxin pyocyanin triggers autophagy: Implications for pathoadaptive mutations. Autophagy 12, 1015-1028. doi: 10.1080/15548627. 2016.1170256

Zhang, K., and Kaufman, R. J. (2008). From endoplasmic-reticulum stress to the inflammatory response. Nature 454, 455-462. doi: 10.1038/nature07203

Conflict of Interest: The authors declare that the research was conducted in the absence of any commercial or financial relationships that could be construed as a potential conflict of interest.

Copyright ( 1021 Tweedie and Nissan. This is an open-access article distributed under the terms of the Creative Commons Attribution License (CC BY). The use, distribution or reproduction in other forums is permitted, provided the original author(s) and the copyright owner(s) are credited and that the original publication in this journal is cited, in accordance with accepted academic practice. No use, distribution or reproduction is permitted which does not comply with these terms. 